\title{
Distraction control processes in free recall: benefits and costs to performance
}

\section{Article}

Accepted Version

Marsh, J. E., Sörqvist, P., Hodgetts, H. M., Beaman, C. P. and Jones, D. M. (2014) Distraction control processes in free recall: benefits and costs to performance. Journal of Experimental Psychology: Learning, Memory \& Cognition, 41 (1). pp. 118-133. ISSN 0278-7393 doi: https://doi.org/10.1037/a0037779 Available at https://centaur.reading.ac.uk/36903/

It is advisable to refer to the publisher's version if you intend to cite from the work. See Guidance on citing.

To link to this article DOI: http://dx.doi.org/10.1037/a0037779

Publisher: American Psychological Association.

Publisher statement: This article may not exactly replicate the final version published in the APA journal. It is not the copy of record

All outputs in CentAUR are protected by Intellectual Property Rights law, including copyright law. Copyright and IPR is retained by the creators or other copyright holders. Terms and conditions for use of this material are defined in the End User Agreement.

\section{www.reading.ac.uk/centaur}


Central Archive at the University of Reading

Reading's research outputs online 
Distraction Control Processes in Free Recall: Benefits and Costs to Performance

John E. Marsh ${ }^{1,2}$, Patrik Sörqvist ${ }^{2,3}$, Helen M. Hodgetts ${ }^{4,5}$, C. Philip Beaman ${ }^{6}$, and Dylan M. Jones ${ }^{7}$

${ }^{1}$ School of Psychology, University of Central Lancashire, Preston, Lancashire, UK.

${ }^{2}$ Department of Building, Energy, and Environmental Engineering, University of Gävle, Gävle, Sweden.

${ }^{3}$ Linnaeus Centre HEAD, Swedish Institute for Disability Research, Linköping University, Linköping, Sweden.

${ }^{4}$ École de psychologie, Université Laval, Québec, Québec, Canada.

${ }^{5}$ Department of Applied Psychology, Cardiff Metropolitan University, Cardiff, UK.

${ }^{6}$ School of Psychology \& Clinical Language Sciences, University of Reading, Reading, UK.

${ }^{7}$ School of Psychology, Cardiff University, Cardiff, UK.

RUNNING HEAD: Distraction Control Processes in Free Recall

IN PRESS:

JOURNAL OF EXPERIMENTAL PSYCHOLOGY: LEARNING, MEMORY \& COGNITION

Correspondence: John E. Marsh, School of Psychology, University of Central Lancashire, Preston, United Kingdom, PR1 2HE., Phone: + 441772 893754, Fax : +44 1772 892925, E-mail: jemarsh@uclan.ac.uk 


\begin{abstract}
How is semantic memory influenced by individual differences under conditions of distraction? This question was addressed by observing how visual target words — drawn from a single category — were recalled whilst ignoring spoken distracter words that were either members of the same, or members of a different (single) category. Working memory capacity (WMC) was related to disruption only with synchronous, not asynchronous, presentation and distraction was greater when the words were presented synchronously. Subsequent experiments found greater negative priming of distracters amongst individuals with higher WMC but this may be dependent on targets and distracters being comparable category exemplars. With less dominant category members as distracters, target recall was impaired - relative to control - only amongst individuals with low WMC. The results highlight the role of cognitive control resources in target-distracter selection and the individual-specific cost implications of such cognitive control.
\end{abstract}

Keywords: Auditory Distraction; Working Memory Capacity; Source Monitoring; Free Recall, Negative Priming, Inhibition. 
To function adaptively in a changing environment, the cognitive system must find a way to attend selectively to information relevant to its present goal while avoiding distraction from irrelevant information. This is a particular problem with irrelevant auditory information. Often, visual distracters can be excluded from the visual field, but this is not generally an option for auditory distracters which are processed obligatorily regardless of where within the environment visual attention is focused. One way to study the cognitive mechanisms of selective attention is by means of a distraction paradigm; for example, within the cross-modal semantic distraction task, the participants are visually-presented with target words belonging to the same category (e.g., 'Fruit') studied either in silence or against a background of to-be-ignored auditory words (distracters) that either belong to the same category as the target items (other 'Fruit') or a different category (e.g., 'Tools'). In this (free recall) task, correct recall is impaired when target and distracter words are members of the same category (Neely \& LeCompte, 1999), and confidence in forced judgments is also reduced (Beaman, Hanczakowski \& Jones, 2014). Furthermore, intrusions of distracters into the recall protocol are also observed (Beaman, 2004; Neely \& LeCompte, 1999; Marsh, Hughes, \& Jones, 2008, 2009; Sörqvist, Marsh, \& Jahncke, 2010b; for comparable effects using phonologically defined (e.g., rhyme) categories, see Marsh, Vachon, \& Jones, 2008).

The cross-modal semantic distraction paradigm provides a useful tool with which to explore key phenomena involved in the selection of an item from a range of possible items which might also provide a reasonable semantic "fit" to the target (see studies of source-monitoring, Marsh et al., 2008; fluency in verbal retrieval, Jones, Marsh, \& Hughes, 2012; Marsh \& Jones, 2010; and hemispheric specializations of language processing in terms of semantic and non-semantic selection processes, 
Beaman, Bridges \& Scott, 2007; Marsh, Pilgrim, \& Sörqvist, 2013; Sörqvist et al., 2010b). Here, we use the paradigm to explore how the cognitive system controls, through selective attention, the successful retrieval of visual target material (Hughes \& Jones, 2003; Marsh, Beaman, Hughes, \& Jones, 2012). We examine how this control process (co-) varies with the particular disposition of the individual for attentional control and what consequences, if any, cognitive control may have for the recall of target information.

It is perhaps surprising that individual differences in working memory capacity (WMC) - measured with complex span tasks that combine short-term memory processes with concurrent distracter activities - seem unrelated to crossmodal semantic disruption (Beaman, 2004). The puzzle here is that individual differences in WMC are typically found to modulate auditory distraction as studied in other paradigms (e.g., Sörqvist, 2010a, 2010b; but see Sörqvist, Marsh, \& Nöstl, 2013) and are generally related to performance in situations wherein "task success is aided by inhibiting not only task-specific information but also irrelevant thoughts and distracting events" (Redick, Heitz, \& Engle, 2007, pp. 127). For example, Conway, Cowan and Bunting (2001) found that low-WMC participants were more likely to report hearing their own name on a supposedly unattended channel during a dichotic listening task.

Consonant with the idea that individual differences in WMC reflect the ability to control distraction (Engle, 2002), Sörqvist, Stenfelt and Rönnberg (2012) showed that a greater focus on a to-be-attended channel (a visual-verbal source in this case) resulted in greater inhibition of irrelevant (neural) auditory processing, especially in high-WMC individuals. This supports the idea that low-WMC individuals have poorer inhibitory capabilities, thus failing to inhibit the auditory material at early 
perceptual processing stages (Sörqvist et al., 2012; see also Tsuchida, Katayama, \& Murohashi, 2012). Evidence also suggests that high WMC attenuates the disruptive effect that a deviating sound (e.g., the sound ' $\mathrm{m}$ ' in the sequence ' $\mathrm{k} \mathrm{k} \mathrm{k} \mathrm{k} \mathrm{m} \mathrm{k} \mathrm{k} \mathrm{k')}$ has on task performance (Hughes, Hurlstone, Marsh, Vachon \& Jones, 2013; Sörqvist, 2010a; Sörqvist, Nöstl, \& Halin, 2012; Sörqvist et al., 2013). Moreover, although WMC does not appear to modulate the effect of semantic similarity between targets and distracters on correct recall, both WMC and age modulate the false recall of semantically-related distracters, with high-WMC participants (Beaman, 2004) and younger adults (Bell, Buchner, \& Mund, 2008) showing fewer intrusions.

Collectively, these studies suggest that the capacity to focus attention on target material and the capacity to inhibit to-be-ignored material are distinguishing features of individuals who vary in WMC. However, if failure to adequately inhibit the processing of to-be-ignored distracters is the distinguishing feature of low-WMC individuals (e.g., Heitz \& Engle, 2007; Kane \& Engle, 2000), then why does WMC not modulate the damaging impact of related distracters on correct recall in the crossmodal semantic distraction paradigm?

One possibility is that the disruption to correct recall by related distracters is governed by target-distracter selection processes. In the study by Beaman (2004), the distracters were presented in a retention interval between target encoding and recall. In this situation, the targets and distracters are easy to distinguish temporally and contextually, and target encoding does not necessitate concurrent distracter inhibition (Marsh et al., 2008). A key idea in the present study is that (undesired) sound processing reduces visual target processing (Weisz \& Schlittmeier, 2006), when auditory and visual material are presented concurrently, and WMC serves to distinguish relevant from irrelevant material within temporally-bounded windows or 
search sets (cf. Unsworth \& Engle, 2007). This can happen both at retrieval - in which case the window is relatively wide [resulting in the WMC- and age-related differences in intrusions reported by Beaman (2004) and Bell et al. (2008) during a retention interval] - and also at encoding - in which case the window is not a search set but rather an attentional focus, and thus is relatively narrow. Thus, any impact of WMC is most likely to be seen when targets and distracters are presented in phase, that is, synchronously — than if presented asynchronously. This reasoning suggests an effect of synchrony of presentation which has not previously been investigated in semantic distraction studies, and was not found in studies using serial short-term recall (e.g., Salamé \& Baddeley, 1982). However, serial memory effects are not mediated by the semantic-relatedness between distracters and targets (Buchner, Irmen, \& Erdfelder, 1996); thus if high-WMC individuals exercise greater control specifically over semantic activation within memory (e.g., as a result of superior inhibition; Rosen \& Engle, 1998), then this might impact on semantic memory regardless of the effects on serial, episodic and short-term memory.

To preview the present study, we provide the first tests of the hypothesis that the between-sequence semantic similarity effect is modulated by individual differences in cognitive control, as measured by WMC. In Experiment 1 we first seek support for the hypothesis that differences in the susceptibility to the betweensequence semantic similarity effect occur when target and distracter representations are maximally co-active - as with synchronous presentation - such that the system has to select one source of activated representation (that emanating from visual origin) over another (that arising from auditory origin) in the absence of distinctive temporal cues. In Experiments 2-4, we further address the capacity for cognitive control using a negative priming (NP) paradigm (Marsh et al., 2012); that is, a setting in which to-be- 
ignored auditory distracters on trial $n$ then become target items on trial $n+1$. NP is measured by the impairment in performance when previously ignored distracters are used as to-be-remembered items, relative to new items. Further, we test the hypothesis that differences in cognitive control—as measured by WMC — - will be observed when the distracters are strong competitors for recall. This is presumed to be the case when distracters are high in output-dominance (i.e., frequently given as an example of a category in category-norm studies) and hence (according to the strength-dependent competition assumption) potentially more interfering than if distracters are low in output dominance (Anderson, Bjork, \& Bjork, 1994). This pattern of results would strongly support the view that WMC reflects the efficiency of cognitive control processes, such as distracter-inhibition, in modulating specifically semantic distraction.

\author{
Experiment 1 \\ Method
}

\title{
Participants
}

Seventy-six students (40 from Cardiff University and 36 from the University of Central Lancashire) took part in the study. All reported normal or corrected-tonormal vision and normal hearing, and spoke English as their first language. They received course credit or an honorarium for their participation.

\section{Apparatus/Materials}

The experiment was run using Superlab Pro (Cedrus Corporation) software. Across two sessions, participants received 36 trials in which they were presented with 15 to-be-remembered words (targets) and 15 to-be-ignored words (distracters). Targets appeared centrally on the computer screen in black 72-point Times font on a 
white background at a rate of one every $1.5 \mathrm{~s}$ (750 ms on, with a $750 \mathrm{~ms}$ interstimulus interval; ISI). Distracters were presented over stereo headphones at $65 \mathrm{~dB}(\mathrm{~A})$ and at a rate of one every $1.5 \mathrm{~s}$ (750 ms on, $750 \mathrm{~ms}$ ISI). Depending on the condition, the distracters were either presented synchronously with the distracters (Synchronous condition) or in the ISI between the targets when a blank (white) screen was presented (sandwiched between targets during study; Asynchronous condition). The distracters were digitally recorded in a male voice at an even-pitch and sampled with a 16-bit resolution at a sampling rate of $44.1 \mathrm{kHz}$ using Sound Forge 5 (Sonic Inc., Madison, WI, 2000).

Thirty words were chosen from each of 36 semantic categories taken from the Van Overschelde, Rawson, and Dunlosky (2004) category norms. Items from oddranked positions in the category-norm lists were assigned to the to-be-recalled (TBR) target lists and items from even positions were to-be-ignored (TBI) distracters. The 36 selected categories were first arranged into pairs of unrelated categories (e.g., "Fruit", “Carpenter's Tools”).

There were two experimental blocks that were separated by one week. There were 18 trials in both blocks respectively: 9 in which targets and distracters were semantically related and 9 in which they were unrelated. On the related trials, in the first block, the auditory distracters were taken from the same category as the targets, thus only one of the categories in the pair was presented. On unrelated trials, both categories in the pairs were presented. Thus the distracter items were taken from the semantically-unrelated category (e.g., "Fruit") that was paired with the target category ("Carpenter's Tools"). For the second block of 18 trials, the related trials incorporated the categories that were not used on the related trials in the first block. For example, if the pair was Fruit and Carpenter's tools, and Fruit was used as the category in block 1, 
then Carpenter's tools was used in block 2. For the unrelated trials in block 2, the same category-pairs were used as in block 1, but the items that acted as targets in block 1 were presented as distracters in block 2 and the items that acted as distracters in block 1 were presented as targets in block 2 .

The presentation order of exemplars within each to-be-remembered and to-beignored sequence was random but the same for each participant. Half of the participants received a semantically-related trial first, followed by a semanticallyunrelated trial (with trials alternating thereafter between related and unrelated even across blocks), whereas this order was reversed for the other half of the participants. Moreover, half of the participants started with the Synchronous block and half started with the Asynchronous block. Categories were assigned such that across participants there was an equal likelihood of each category being an unrelated or related category, presented in the Synchronous or Asynchronous condition, and experienced in block 1 or block 2 of the experiment.

Design

A 2 (Phase of Presentation: synchronous versus asynchronous) $\times 2$ (TargetDistracter Relation: related versus unrelated) within-participants design was used. The dependent variables were (a) the proportion of target words correctly recalled and (b) the number of intrusions; that is words recalled that did not appear as targets on a given list.

\section{Procedure}

Participants were first tested for their operation span (OSPAN) using an automated OSPAN program (see Unsworth, Heitz, Schrock, \& Engle, 2005). For this task, the participants were visually-presented with lists of mathematical-operation questions (e.g., "Is $7 \times 5+3=38$ ?") and to-be-recalled letters. The participants' task 
was to respond with a 'yes' or a 'no' to each question and to select the to-be-recalled letters in order of presentation from an array at the end of each list. OSPAN score was used as an indicator of WMC. Participants were then tested individually in soundproof booths and were seated at a distance of approximately $60 \mathrm{~cm}$ from a PC monitor. Participants wore headphones throughout the experiment. Participants began by reading standardized instructions and they were told specifically that they should ignore the distracter words and that they would not be asked anything about them during the experiment. They were given response booklets in which to recall the target words (a grid with space for 15 words was provided for each trial).

The target words were presented one at a time on the computer screen and after all 15 targets (and 15 distracters) had been presented, the computer displayed the prompt "recall" on the screen. Participants then had $45 \mathrm{~s}$ to write down on the response sheets, in any order, as many of the target items as they could. Through instructions, guessing on the task was explicitly discouraged. After the $45 \mathrm{~s}$ recall period, a tone in the headphones signalled the end of the trial. Pressing the space bar initiated presentation of the next list. One practice trial (in quiet) was given at the start of each block after which participants had the opportunity to ask any questions before the main trials began. The first experimental session lasted approximately $50 \mathrm{~min}$ and the second took about $30 \mathrm{~min}$.

\section{Results}

Absolute OSPAN scores were computed (see Unsworth et al., 2005). When four extreme outliers were removed, the mean OSPAN score was 39.07 ( $S E=1.58$, range $14-69, N=72)$. The skewness was $.16(S E=.28)$ and the kurtosis was $-.51(S E$ $=.56)$.

\section{Correct responses}


Responses were scored according to a free recall criterion; an item was scored as correct regardless of its position. As can be seen in Figure 1 (Panel A), proportion correct recall was impaired by the presence of to-be-ignored words that belonged to the same category as the to-be-recalled items in comparison with when the to-beignored words belonged to a different category, and more so when presentation of the target and non-target items were synchronous. Skewness and kurtosis for the four experimental conditions were fairly normal (synchronous related $=0.32$ and 0.31 ; synchronous unrelated $=-0.003$ and $-0.09 ;$ asynchronous related $=-0.21$ and -0.31 ; asynchronous unrelated $=-0.17$ and -0.35 , respectively). In the following analysis we use a covariate as a straightforward way of combining a continuous variable (the OSPAN scores) with the factorial analysis (i.e., addressing the potential interaction between target-distracter similarity and synchronicity). This analysis makes it possible to test if an interaction is present when we statistically control for WMC. If the interaction is present then this means that the interaction is also present under the assumption that all participants have the same WMC. Moreover, at the same time we can also test if factors interact with WMC. If there is indeed an interaction, this means that the magnitude of the effect of the factors depends on individual differences in WMC. The analysis with the covariate is then followed up so that any interactions with OSPAN can then be understood.

A 2 (Phase of Presentation: synchronous versus asynchronous) $\times 2$ (TargetDistracter Relation: related versus unrelated) analysis of co-variance (ANCOVA) with OSPAN as a covariate variable revealed a main effect of Phase of Presentation, $F(1,70)=7.08, M S E=0.003, p<.0097, \eta_{\mathrm{p}}{ }^{2}=.09$, a main effect of Target-Distracter Relation, $F(1,70)=33.96, M S E=0.001, p<.001, \eta_{\mathrm{p}}{ }^{2}=.33$, and a significant interaction between these two factors, $F(1,70)=20.20, M S E=0.001, p<.001, \eta_{\mathrm{p}}{ }^{2}=$ 
.22. OSPAN interacted significantly with Target-Distracter Relation, $F(1,70)=4.58$, $M S E=0.001, p=.036, \eta_{\mathrm{p}}^{2}=.06$, with Phase of Presentation, $F(1,70)=5.59, M S E=$ $0.003, p=.021, \eta_{\mathrm{p}}{ }^{2}=.07$, and the three-way interaction was significant, $F(1,70)=$ 14.13, MSE $=0.001, p<.001, \eta_{\mathrm{p}}^{2}=.17$. Control analyses with Block Order (synchronous versus asynchronous first) as an additional factor revealed no main effect of Block Order and none of its interactions with Phase of presentation and/or Target-Distracter Relation was statistically significant.

To tease apart the three-way interaction, we obtained a person-specific measure of susceptibility to semantic auditory distraction (the "between-sequence semantic similarity effect”) by subtracting the total number of correct recalls in the related speech condition from correct recalls in the unrelated speech condition (i.e., a larger value represents a larger effect $)$, in the synchronous $(M=0.064, S D=0.062$; skewness $=-0.36 ;$ kurtosis $=-0.03 ; \alpha=.91)$ and asynchronous $(M=0.039, S D=$ 0.046; skewness $=-0.11 ;$ kurtosis $=0.37 ; \alpha=.95)$ conditions. These difference scores were correlated with OSPAN. As can be seen in Figure 2 (panel A), higher OSPAN scores were associated with a lower magnitude of the between-sequence semantic similarity effect with synchronous presentation, $r(70)=-.41, p<.001,95 \%$ CI $[-.63$, -.19], but no relationship was found with asynchronous presentation (panel B), $r(70)=$ $.14, p=.24,95 \%$ CI $[-.09, .38]$. Notably, these two correlation estimates are significantly different (Meng, Rosenthal, \& Rubin, 1992) ${ }^{1}, z(70)=3.28, p<.001,95$ $\%$ CI $[.23, .73]$. Hence, WMC modulates the between-sequence semantic similarity effect with synchronous presentation but not with asynchronous presentation.

\section{Intrusions}

We also analysed false recalls of spoken distracter words that appeared in the recall protocols. The frequency of these intrusion errors is related to WMC (Beaman, 
2004). A response that matched one of the fifteen items from the even positions in the Van Overschelde et al. (2004) norms (that were presented as distracters on related trials) was scored as an intrusion, even for the unrelated condition in which those items had not been presented, which provides an estimate of false recall probability (see Beaman, 2004; Marsh et al., 2008). Figure 1 (panel B) shows the mean number of related-item intrusions for each condition. Skewness and kurtosis for the four experimental conditions were relatively high, as is typical with these dependent variables ( synchronous related $=1.43$ and 2.57 ; synchronous unrelated $=1.60$ and 4.41 ; asynchronous related $=1.24$ and $1.99 ;$ asynchronous unrelated $=2.00$ and 7.31 , respectively).

A 2 (Phase of presentation: synchronous versus asynchronous) $\times 2$ (TargetDistracter Relation: related versus unrelated) ANCOVA with OSPAN as a covariate revealed a main effect of Phase of Presentation, $F(1,70)=57.30, M S E=8.11, p<$ $.001, \eta_{\mathrm{p}}{ }^{2}=.45$, a main effect of Target-Distracter Relation, $F(1,70)=84.60, M S E=$ $2.77, p<.001, \eta_{\mathrm{p}}{ }^{2}=.55$, and a significant interaction between these two factors, $F(1$, $70)=85.76, M S E=2.75, p<.001, \eta_{\mathrm{p}}{ }^{2}=.55$. Again, OSPAN interacted significantly with Target-Distracter Relation, $F(1,70)=37.64, M S E=2.77, p<.001, \eta_{\mathrm{p}}{ }^{2}=.35$, with Phase of Presentation, $F(1,70)=16.26, M S E=8.11, p<.001, \eta_{\mathrm{p}}{ }^{2}=.19$, and the three-way interaction was significant, $F(1,70)=37.47, M S E=2.75, p<.001, \eta_{\mathrm{p}}{ }^{2}=$ .35. Again, control analyses with Block Order revealed no main effect or interactions with this factor.

To obtain a person-specific measure of susceptibility to intrusions from speech, the total number of intrusions (false recalls) in the unrelated speech condition was subtracted from intrusions in the related speech condition (i.e., larger values represent greater susceptibility), in the synchronous $(M=4.17, S D=4.09$; skewness $=$ 
$1.25 ;$ kurtosis $=1.97 ; \alpha=.57)$ and asynchronous $(M=2.99, S D=3.00 ;$ skewness $=$ 0.09 ; kurtosis $=0.26 ; \alpha=.63$ ) conditions separately. As can be seen in Figure 3, higher OSPAN scores were associated with a lower susceptibility to intrusions from speech both with synchronous presentation (panel A), $r(70)=-.59, p<.001,95 \%$ CI $[-.78,-.40]$, and with asynchronous presentation (panel B), $r(70)=-.33, p=.005,95$ $\%$ CI [-.56, -..11]. This replicates previous findings of a relationship between WMC and semantically-related intrusions regardless of synchrony of targets and distracters (Beaman, 2004). However, these two correlation estimates are significantly different in magnitude (Meng et al., 1992), $z(70)=2.46, p=.014,95 \%$ CI [.07, .54]. It should be noted, though, that the high skewness values of the difference scores in the synchronous condition could have distorted this comparison. In all, WMC constrains susceptibility to intrusions from speech, both with synchronous and asynchronous presentation, and there is indication that WMC does so to a greater extent with synchronous presentation.

To further elucidate how WMC constrains the window of attentional focus and processing at encoding, a dominance analysis was performed whereby each intrusion was assigned a dominance value based upon frequency of production within category norms (Van Overschelde et al., 2004). Where participants made no intrusions this was treated as missing data. The mean dominance of intruding exemplars was $0.32(S D=$ $0.20 ; N=70)$ in the related target-distracter relation condition, $0.37(S D=0.22 ; N=$ $61)$ in the unrelated synchronous condition, $0.32(S D=0.19 ; N=71)$ in the related asynchronous condition, and $0.43(S D=0.20 ; N=62)$ in the unrelated asynchronous condition. OSPAN was positively correlated to the dominance of intruding exemplars in the related target-distracter relation condition with synchronous presentation, $r(68)$ $=.33, p=.006$. Corresponding correlations in the other conditions were very weak 
(unrelated synchronous, $r=-.07$, related asynchronous, $r=.02$, unrelated asynchronous, $r=.04)$. Hence, lower WMC was associated with a greater tendency to falsely recall low-dominant exemplars, but only under conditions of synchronous presentation of targets and distracters. The relationship between WMC and false recall cannot therefore be dismissed as a by-product of enhanced (but inaccurate) guessing associated with poorer overall recall by low WMC individuals. Moreover, the finding that lower WMC was associated with a greater tendency to recall low-dominant exemplars is consistent with the notion that for lower WMC individuals, those lowdominant distracters reach higher activation thresholds.

\section{Discussion}

Experiment 1 demonstrated that the between-sequence semantic similarity effect is greater when the targets and distracters are synchronously presented, and that this relationship is moderated by WMC. This was reflected in a greater rate of intrusion of related distracters and, strikingly, diminished correct recall with synchronous relative to asynchronous presentation for low-WMC individuals. Overall, the pattern of data is consistent with the notion that participants with weaker cognitive control (e.g., lower inhibitory capabilities) correctly recall fewer target items, but only when the target-selection processes is challenged by the simultaneous presence of distracters. In Experiment 2, we sought further, and this time more direct, evidence for the assumption that the distracters are indeed subject to a greater degree of cognitive control by high-WMC individuals..

\section{Experiment 2}

In a recent set of experiments, Marsh et al. (2012) used a NP paradigm (Figure 4) to investigate the possible role of inhibition in semantic auditory distraction. In this 
study, free recall was impaired for target items in trial $n+1$ (the probe trial) if they had served as distracters on trial $n$ (the prime trial). However, this NP effect only occurred if the targets at probe were high output-dominant members of the same category as the to-be-recalled items when presented as distracters at prime (Marsh et al., 2012, Experiment 2). For prime trials in which distracters were low output-dominant members of the to-be-remembered category, or were unrelated to that category, recall was enhanced rather than impaired when those same distracters were presented as tobe-recalled items on the probe trial (positive priming; PP). In other words, distracters were less well recalled when, at prime, they were strong competitors for retrievalsuch as when they represented high-dominant category members-but not when they were weak competitors, such as when they represented low-dominant category members.

Evidence that distracter inhibition is resource-dependent has been found in the context of perceptually-based NP. For example, de Fockert, Mizon and D'Ubaldo (2010) report that the availability of cognitive control resources appears to be a prerequisite for NP. Moreover, NP has been shown to be stronger in high-WMC individuals (Conway, Tuholski, Shisler, \& Engle, 1999), suggesting that individuals with superior cognitive control capabilities (high-WMC individuals) inhibit distracters at prime to a greater degree than their low-WMC counterparts. Using this evidence as the basis for hypothesizing, the magnitude of NP produced by semantic auditory distracters should increase as a function of individual differences in WMC. HighWMC individuals should more effectively inhibit the semantic distracters and subsequently show stronger NP, but only when the distracters are strong competitors for recall (namely, high output-dominant exemplars), or are matched in outputdominance with the targets such that retrieval heuristics are difficult to deploy (as in 
Experiment 1). In Experiment 2 we adopt a very similar design to the synchronous condition within Experiment 1 with the exception that in the critical, ignored repetition probe trials, the related speech distracters were re-presented as to-beremembered targets on the very next trial (cf. Marsh et al., 2012). Therefore, as in Experiment 1, the targets and distracters were comparable in terms of outputdominance.

\section{Method}

\section{Participants}

Seventy-two students at the University of Central Lancashire took part in the study. All reported normal or corrected-to-normal vision and normal hearing, and spoke English as their first language. They received a small honorarium for their participation.

\section{Materials \& Design}

Within the block of 36 trials used in the current experiment, $50 \%$ of the trials comprised "prime" trials and 50\% were "probe" trials. Prime trials were accompanied by distracters whereas no distracters were presented for probe trials.

Thirty words, taken from rank positions 1 to 30, were chosen from each of 36 semantic categories in the Van Overschelde et al. (2004) category norm lists. Each participant received 36 trials comprising one list of 15 visually to-be-remembered words per trial. Half of these were designated as prime trials, and half as probe trials. The experiment was run using E-Prime 2 (Psychology Software Tools Inc.) software. As in Experiment 1, participants were first tested for their operation span (OSPAN) using an automated OSPAN program (see Unsworth et al., 2005). The task was scored 
using a strict serial recall criterion by assigning one point to each item recalled in the correct serial position.

Prime trials. On prime trials, 15 auditorily-presented to-be-ignored (TBI) words (distracters) were presented alongside the to-be-remembered (TBR) items. TBR items were presented, one item at a time, on the computer screen in lower-case 72-point Times font on a white background at a rate of one every $1.5 \mathrm{~s}(750 \mathrm{~ms}$ on, with a $750 \mathrm{~ms}$ inter-stimulus interval; ISI). TBI auditory distracters were presented synchronously with visual to-be-remembered items. In 9 of these trials, the distracter lists were semantically-related to the to-be-remembered lists. To achieve this, 15 items from odd-ranked positions $(1,3,5 \ldots)$ from the Van Overschelde et al. (2004) category norm lists were assigned to the distracter lists and items from the even positions $(2,4,6 \ldots)$ were assigned to the TBR lists (e.g., for the category "fruit", the TBI lists would be \{apple [1], banana [3], pear [5] etc and the TBR lists would be \{orange [2], grape [4], peach [6] etc\}). On the remaining nine trials, the auditory distracter items were drawn from categories other than those from which the TBR items were drawn (e.g., if the TBR list was from the category "fruit", as above, the distracter list might be from the category "tools", giving the items \{hammer [1], saw [2], drill [3] etc\}). Within lists, all items were randomized with respect to their original ranked positions in the Van Overschelde et al. (2004) norms. This random order was the same for all participants.

TBR category lists were also presented to participants in one of two orders (e.g., half the participants might have the category "fruit" as the basis for the TBR items on trial 1, and half might have the category "tools"). The presentation of distracters that were related or unrelated to these lists was counterbalanced across participants such that any given category was presented equally often in the presence 
of related distracters and unrelated distracters (resulting in four possible combinations across participants for trial 1: fruit (TBR)-fruit (TBI); fruit (TBR)-tools (TBI); tools (TBR)-tools (TBI); tools (TBR)-fruit (TBI)).

Probe trials. A prime trial with auditory distracters accompanying the visual TBR list (18 of the 36 trials) was always immediately followed by a probe trial with no accompanying auditory distracters (the remaining 18 trials). The visually-presented list of TBR items on 9 of these probe trials exactly replicated the auditorily-presented list of distracter items from the preceding prime trial (ignored repetition trials), albeit these items were now presented in a different order. These ignored repetition probe trials always followed prime trials in which the auditory distracters and to-beremembered lists were semantically-related.

On 9 probe trials that acted as a control condition, the TBR list comprised items taken from the same semantic category as the TBR list on the previous trial, and therefore categorically-unrelated to the auditory distracters heard previously (see Figure 4). For these trials, the TBR items were drawn from the odd positions (up to position 29) of the semantic category seen previously as TBR material. For example, if the TBR items at prime came from the even positions (up to position 30) of the category "animals" within the Van Overschelde et al. (2004) norms (cat[2], lion [4]...) then the TBR items on a control "probe" trial would be dog[1], horse[3] and so on. Thus, to control for proactive interference, the semantic categories - but not particular items - were repeated across prime and probe lists in all conditions. Pairs of trials were alternated between those that incorporated prime trials followed by ignored repetition trials, and those that incorporated prime trials followed by no-repetition (of distracters). The experimental session took approximately $50 \mathrm{~min}$. 


\section{Results}

The mean OSPAN score was $40.50(S E=1.87$, range $6-75, N=72)$. The skewness was $.07(S E=.28)$ and the kurtosis was $-.57(S E=.56)$.

\section{Correct responses}

Correct responses were scored the same way as in Experiment 1. As shown in Table 1, a between-sequence semantic similarity effect (poorer recall in the related $v s$. unrelated speech condition in the prime trials), and a NP effect, were found. There was poorer recall in the ignored repetition probe condition (wherein the distracter items on the previous trial were repeated as targets) $v s$. the control condition (wherein the target items were taken from the same semantic category as the target items on the previous trial but were not presented as distracters on that previous trial).

To test whether the magnitude of NP and the between-sequence semantic similarity effects were correlated, and whether individual differences in WMC modulate individual differences in the magnitude of these effects, difference scores were calculated to obtain person-specific measures of the magnitude of NP ( $\alpha=.78)$ and the between-sequence semantic similarity effect $(\alpha=.89$; Table 1$)$. Cognitive control appears to protect correct recall against disruption (Figure 5), as a smaller between-sequence semantic similarity effect (i.e., less disruption of short-term recall), $r(70)=-.40, p<.001$ was associated with a greater NP effect (i.e., greater distracter inhibition). Moreover, WMC was positively correlated with the NP effect, $r(70)=.65$, $p<.001$ (Figure 6), and negatively correlated with the between-sequence semantic similarity effect, $r(70)=-.35, p=.002$ (Figure 7).

\section{Intrusions}

We also analysed the relation between WMC and the tendency to falsely report the distracters at recall as if they were targets. The mean number of intrusions 
from the speech (related-item intrusions, or "distracter intrusions") on the prime trials can be seen in Table 2. As in Experiment 1, intrusions were more common in the related speech condition than in the unrelated speech condition, and OSPAN was negatively correlated with the person-specific score for susceptibility to intrusions, $r(70)=-.39, p<.001$, consistent with Experiment 1 and with Beaman (2004).

As a measure of cognitive control across trials, we also computed the number of prior-list intrusions: That is, responses from the prime target list given amongst responses when tested on the probe target list (see Table 2). These were few in number but slightly more common for control probe trials than for ignored repetition probe trials. OSPAN was negatively correlated with the number of intrusions in the ignored repetition condition, $r(70)=-.39, p=.001$, but positively related to them in the control condition, $r(70)=.24, p=.046$.

\section{Discussion}

The results of Experiment 2 seem altogether consistent with the notion that distracters undergo inhibition, and individuals with higher WMC are able to inhibit them to a greater extent than individuals with low WMC, wherein correct recall is more protected in high-WMC individuals and false recall is reduced. A close inspection of Figures 5-7 suggests that the strong relationship between NP and WMC could have emerged because individuals with lower WMC show PP whereas individuals with high WMC demonstrate NP. Subsequent PP is associated with a large between-sequence semantic similarity effect on the previous trial and subsequent NP is associated with a smaller previous between-sequence semantic similarity effect. 
At first glance, these results appear inconsistent with those of Marsh et al. (2012) which did not find a correlation between NP and the between-sequence semantic similarity effect, whereas a negative correlation was found in Experiment 2. One possible reason for the inconsistency is the larger sample size - and concomitant increased statistical power-adopted for the current experiment. Another way in which the findings can be reconciled with the earlier findings of Marsh et al. (2012) is that the relationship between NP and the between-sequence semantic similarity effect holds primarily when retrieval heuristics based on output-dominance are prevented: When the targets and distracters are equivalent in terms of output-dominance, there is an easy cue — based on item-strength — to identify the targets from amongst the distracters at recall so distracters are need not be inhibited. A third possibility is that the relationship between the NP and the between-sequence semantic similarity effect co-varies with individual differences in cognitive control as indexed by WMC. Since cognitive control varies with WMC, any relationship between NP and the betweensequence semantic similarity effect may only become evident when individual differences in cognitive control are taken into consideration. These possibilities are explored in Experiment 3 wherein the targets and distracters from Experiment 2 were rearranged such that the targets at prime were low output-dominant (goat[16], zebra[17]...) and the distracters were high output-dominant (dog[1], cat[2]...).

\section{Experiment 3 \\ Method}

This was the same as Experiment 2, with the exceptions noted. Forty students at Cardiff University, and thirty-two at the University of Central Lancashire, took part in the study. All reported normal or corrected-to-normal vision and normal hearing, 
and spoke English as their first language. They received course credit for their participation. None had participated in Experiments 1 and 2.

Complex-span tasks. Two complex-span tasks were used to assess working memory capacity: operation span (OSPAN; Turner \& Engle, 1989) and sizecomparison span (SICSPAN; Sörqvist et al., 2010). In the OSPAN task used here, the participants were visually-presented with lists of mathematical-operation questions (e.g., "Is $7 \times 5+3=38$ ?") and to-be-recalled words (e.g., DOG). The participants' task was to respond with a 'yes' or a 'no' to each question and to recall the to-berecalled words in order of presentation at the end of each list. In SICSPAN, the participants were presented with lists of comparison questions (e.g., "Is LION larger than CAT?") and to-be-recalled words (e.g., MOUSE). The participants' task was the same as for the OSPAN task. In both tasks, the total number of to-be-recalled words for each list varied between 2 and 6. There were 3 lists of each length in both tasks (see Sörqvist et al., 2010, for full task details). The two span tasks were conducted in counterbalanced order across participants. Participants undertook the NP task first and came back the next day to complete the two complex-span tasks.

\section{Procedure}

The Procedure was the same as in Experiment 2.

\section{Results}

The complex-span tasks were scored by assigning one point to each item recalled in the accurate list position (as in Experiments 1 and 2). To increase construct validity, we obtained two separate measures of WMC in Experiment 3 (OSPAN and SICSPAN) and calculated a composite score to be used in the analyses. These two tasks are typically highly and positively correlated (e.g., Sörqvist et al., 2010). This was also the case in Experiment 3, $r(70)=.74, p<.001$. Therefore, for each 
participant, a mean task score across the two complex-span tasks was calculated to create a WMC index. The resulting index was used in the statistical analyses. When one extreme outlier, substantially lower than the sample mean (i.e., WMC z-score = 2.96), was removed, the mean WMC composite score (divided by number of trials) was $.73(S E=.02$, range $.41-.99)$.

\section{Correct responses}

Correct responses were scored the same way as in Experiments 1 and 2. As shown in Table 1, the between-sequence semantic similarity effect (poorer recall in the related $v s$. unrelated speech condition in the prime trials) and the NP effect were again replicated, as indexed by poorer recall in the distracter-repetition probe condition (wherein the distracter items on the previous trial were repeated as targets) $v s$. the control condition (wherein the target items were taken from the same semantic category as the target items on the previous trial, but were not presented as distracters on that previous trial).

As in Experiment 2, we calculated difference scores to obtain measures of the magnitude of the between-sequence semantic similarity effect $(\alpha=.90)$ and the NP effect $(\alpha=.87$; Table 1$)$. A positive correlation was revealed between WMC composite scores and the NP effect magnitude, $r(69)=.43, p<.001$. Also, higher WMC was again associated with a smaller between-sequence semantic similarity effect, $r(69)=-.30, p=.011$. However, there was no significant relationship between the magnitudes of the two effects, $r(69)=.15, p=.216$.

These findings raise the question of whether there is a relationship between $\mathrm{NP}$ and the between-sequence semantic similarity effect when individual differences in cognitive control capacity are statistically controlled. The two effects should be positively related if NP is (at least in part) a cost experienced as a result of distracter 
inhibition or any similar cognitive control mechanisms employed to resist semantic distraction. To test this hypothesis, a multiple regression analysis was conducted with scores for the between-sequence semantic similarity effect as the dependent variable, and the WMC composite score and the NP effect scores as two independent variables. In this model, greater NP was indeed strongly associated with a greater betweensequence semantic similarity effect, as it accounted significantly for a unique set of variance, $\beta=.38, t=3.08, p=.003$ (Figure 8). However, higher WMC was also associated with a smaller between-sequence semantic similarity effect, $\beta=-.48, t=-$ $3.92, p<.001$. In sum, the low-WMC individuals show substantial semantic auditory distraction, and little NP, whereas the high-WMC individuals show less semantic auditory distraction, and substantial NP. For this former group, the distraction effect is presumably a consequence of failure to inhibit, or otherwise control, interference. For the latter group, the distraction effect is (at least partly) a cost arising from the cognitive overheads of successful distracter-inhibition. Similarly, the NP effect is either the residual consequence of successful inhibition as originally theorized (Marsh et al., 2012) or else expanding resources on successful cognitive control - including possibly inhibitory processing - renders more able individuals particularly vulnerable to other forms of interference (Hanczakowski, Beaman \& Jones, 2014).

\section{Intrusions}

The mean number of intrusions from the speech (related-item intrusions, or "distracter intrusions") on the prime trials can be seen in Table 2. As in Experiments 1 and 2, intrusions were more common in the related speech condition than in the unrelated speech condition. WMC was negatively, but weakly, correlated with the person-specific score for susceptibility to intrusions, $r(70)=-.19, p=.05$ (one-tailed). As a measure of proactive interference across trials, we again computed the number of 
prior-list intrusions (see Table 2). As in Experiment 2, these were few in number but were again slightly more common for control probe trials than for ignored repetition probe trials. OSPAN was not correlated with the number of intrusions in the ignored repetition condition, $r(70)=-.02, p=.85$, and only weakly related to intrusions in the control condition, $r(70)=-.19, p=.05$ (one-tailed), perhaps indicating that the difference in item-strength between targets and distracters acted as a good distinctiveness cue for both low and high WMC individuals.

\section{Discussion}

Experiment 3 is consistent with the assumption that the disruption of correct recall by distracter speech is, in part, a residual cost of distracter inhibition (Marsh et al., 2008). TBR lists, comprising items that had been competitors for retrieval during the previous (prime) trial, were more poorly recalled at the probe trial than nonrepeated lists at the probe trial (the NP effect). We assume, therefore, that the occurrence of NP reflects a legacy of an inhibitory process that acts to reduce competition between targets and distracters at prime (Marsh et al., 2012) or else the process of resisting semantic distraction from auditory stimuli at prime gives a measure of individual vulnerability (depending upon WMC) to proactive interference at probe (Hanczakowski et al., 2014) In either case, since the strength of the relationship between targets (and distracters) and the parent category from which they are drawn determines the degree of competition (cf. Anderson et al., 1994; Marsh et al., 2008), we would expect the relationship between the between-sequence semantic similarity effect, NP, and its moderation by WMC, to be influenced by reducing the output dominance of the auditory distracters. Therefore, we investigate a scenario in 
which targets and competitors at prime are semantically-related but not (strong) competitors.

In Experiment 4, the targets and distracters from Experiment 3 were rearranged such that the targets at prime were high-dominant (dog[1], cat[2]...) and the distracters were low-dominant (goat[16], zebra[17]...). The magnitude of the between-sequence semantic similarity effect is a function of distracter dominance, and the effect is typically not manifest with low output-dominant distracters (Marsh et al., 2008, Experiment 4; Marsh et al., 2012). However, low-dominant distracters may receive activation by virtue of their semantic relationship with the target (Kiang \& Kutas, 2006; Rosen \& Engle, 1997), producing a blocking effect on the TBR items (Kimball \& Bjork, 2002; Raaijmakers \& Jakab, 2012; Rundus, 1973). Blocking is typically described as an occlusion mechanism. Here, retrieval of a related distracter should strengthen the associative link between the (distracter) item and its retrieval cue (in this case the cue is the parent-category) which is also shared with the targets. Distracter retrieval thereby decreases the relative strength of association between the retrieval cues and list-exemplars, which makes TBR items more difficult to retrieve, but for reasons other than the reduction (or inhibition) of the absolute activation of the TBR item. Since low-WMC individuals show less of an NP effect than high-WMC individuals (Experiments 2 and 3), reflecting less successful engagement with and control of the distracters, the action of low-dominant distracters may block target retrieval for these individuals. Hence, a between-sequence semantic similarity effect may emerge for low- WMC individuals even when the distracters are low-output dominant. If so, there should be a negative relationship between WMC and the between-sequence semantic similarity effect, even in the absence of NP (Marsh et al., 2012). 


\section{Experiment 4}

Method

This was the same as Experiments 2 and 3, with the exception that the distracters at prime were now low-dominant and the targets high-dominant. Thirty-six students at Cardiff University and thirty-six students at the University of Central Lancashire, fulfilling the same criteria as used in Experiments 1, 2, and 3, took part in the study. None had taken part in Experiments 1, 2, or 3.

\section{Results and Discussion}

The complex-span tasks were scored the same way as in Experiment 3. Again, the OSPAN and SICSPAN scores were highly correlated, $r(70)=.81, p<.001$, and therefore a composite score was produced. The resulting mean WMC score (averaged across trials) was $.74(S E=.02$, range .33-.99). A small between-sequence semantic similarity effect was found when considering the prime trials within Experiment 4 (see Table 1). Moreover, there was a small positive — not negative — priming effect of having the low-dominant distracter items re-presented as targets for recall on the ignored repetition probe trials (see Table 1). Note that overall performance was better for high-dominant targets than low-dominant targets. This reflects the usual tendency for recall to be better for high-dominant than low-dominant targets (Marsh et al., 2012).

Magnitude scores for the NP effect $(\alpha=.92)$ and the between-sequence semantic similarity effect $(\alpha=.93)$ were calculated as in Experiments 2 and 3 (Table 1). In Experiment 4, there was no correlation between WMC and the (positive) priming effect magnitude, $r(70)=-.04, p=.751$, and no correlation between the between-sequence semantic similarity effect and the NP effect, $r(70)=.05, p=.698$. 
Higher WMC individuals were, however, less susceptible to the between-sequence semantic similarity effect (Figure 9), $r(70)=-.55, p<.001$. A regression analysis with the between-sequence semantic similarity effect as dependent variable, and WMC scores and the priming effect as independent variable, confirmed that WMC explained a significant portion of the variance, $\beta=-.55, t=-5.48, p<.001$, and the priming effect did not, $\beta=.03, t=0.26, p=.80$. Hence, even though the low-dominant distracters of Experiment 4 produced a small between-sequence semantic similarity effect overall, they only disrupted recall amongst individuals in the low WMC range. Intrusions

False recalls were relatively few in number, but they were significantly more common for the related speech condition than the unrelated speech condition (see Table 2). Using a person-specific measure of susceptibility to intrusions from speech, higher WMC scores were associated with a lower susceptibility to intrusions, $r(70)=$ $-.24, p=.042$, further reinforcing the findings from Experiments 1-3, and extending to include also the situation wherein distracters are low output-dominant category exemplars. Prior-list intrusions (see Table 2) were more numerous here than in Experiment 3, presumably because they were higher in item-strength (outputdominance).

In this case, with low-output dominant distracters, WMC was highly correlated with the number of intrusions in the control condition, $r(70)=-.37, p<$ .001 , but unrelated to intrusions in the ignored repetition condition, $r(70)=-.08, p=$ .524 .

\section{General Discussion}

The series reported here shows that target-distracter competition at target encoding, manipulated by having the distracters presented synchronously or 
asynchronously with the targets, modulates the disruption of free recall, with synchronous presentation being more disruptive. Individual variation in WMC qualifies this synchronicity effect, with higher WMC being associated with a lower disruption to correct free recall than low WMC with synchronous, but not asynchronous, presentation (Experiment 1). The competition at target encodingmost pressing with synchronous presentation - is resolved by cognitive control mechanisms which protect recall to a limited extent (Experiment 3). When the need for cognitive control is reduced, such as when the distracters are weak competitors, the distracters may nevertheless still impair target recall, at least for individuals with poor WMC (Experiment 4).

Notably, no relationship between WMC and distraction of correct recall was found in the study by Beaman (2004) in which distracters were presented during a retention interval. It appears, therefore, that the effect of semantic distraction on correct recall is only modulated by WMC when there is a substantial temporal overlap between the presentation of targets and distracters (Experiment 1).

We assume that the driving mechanism behind this finding is that the selection of targets - and the active deletion of distracters - from the to-be-recalled set is most taxing (i.e., requires a high degree of cognitive control capabilities such as effective distracter inhibition) with synchronous presentation. As high-WMC individuals are more capable of inhibiting or suppressing task-irrelevant processing when the task is cognitively taxing (Sörqvist, Stenfelt, et al., 2012), the relationship between WMC and the between-sequence semantic similarity effect is strongest in this situation. This suggestion sits nicely with the finding that WMC predicts performance on tasks such as cross-modal Stroop whereby target-distracter synchronicity is known to modulate interference effects (e.g., Elliott, Cowan, \& Valle-Inclan, 1998). 
The controversial role of distracter inhibition

In what way is the target-distracter competition resolved? As hypothesized elsewhere (Marsh et al., 2012), the competition may be resolved by distracter inhibition (as manifest in a NP effect). This inhibition process protects correct recall from disruption (as shown by the negative correlation between NP and the betweensequence semantic similarity effect in Experiment 2). From this perspective, the inhibition process itself is associated with an overhead cost as the magnitude of the between-sequence semantic similarity effect was positively correlated with the NP effect in Experiment 3, but only when individual differences in WMC (and thus the ability to inhibit the distracters) were statistically accounted for. At the same time, higher WMC was associated with greater NP when the distracters were high output dominant (and thus competitors for recall). Higher WMC was also associated with a smaller between-sequence semantic similarity effect, both in the presence of distracter inhibition (Experiments 1, 2 and 3) and in the absence of distracter inhibition (Experiment 4).

Taken together, this complex pattern of results suggests that the inhibition process that protects from distraction, can itself impair recall possibly through suppressing shared features of distracter and target representations. For example, Anderson and Spellman's (1995) pattern-suppression model describes how inhibition acts upon sub-symbolic elements (features) of the memory representations of competitors. Features of competitors that are activated during retrieval, but are not components of the target, become suppressed. Competitor items activated during retrieval, therefore, have many features that are subject to inhibition. Moreover, if other competitors possess many of the suppressed features, it follows that those 
competitors will also be subject to inhibition. The pattern suppression model accounts for the finding that high similarity between targets and competitors protects against suppression whereas a low similarity exacerbates inhibition (Anderson, Green, \& McCulloch, 2000). On the pattern suppression model, "banana" has many features that are not components of the retrieved target "orange". These unshared features are inhibited during retrieval of "orange", and hence, the later retrieval of "banana" suffers. However, the competitor "tangerine" as compared to "banana" has many shared, and therefore fewer unshared, features with the target "orange". The shared features are strengthened, not inhibited, as a function of retrieving the target. Since the total inhibition of a representation is a function of the sum of inhibition across all of its features, a competitor with few unshared features will be inhibited less than a competitor with many unshared features. From this perspective, it is relatively straightforward that targets can also be inhibited as a function of sharing many features with the suppressed distracters.

Evidence for the role of distracter inhibition in semantic auditory distraction is further reinforced by the intrusion analysis of Experiments 1 and 4. Search processes are inevitably going to operate across a semantic space when retrieving categorized lists and, therefore, the presence of semantically-related distracters will impede this process (Unsworth \& Brewer, 2010a, 2010b; Unsworth \& Engle, 2007). Consistent with this observation, the intrusion analysis of Experiment 1 shows that the selection processes of low-WMC individuals are less efficient than that of high-WMC individuals, especially when targets and distracters are synchronously presented. This is evidenced by the more frequent presence of (low-dominant) semantically-related distracters in the memory search set of low-WMC individuals and their greater 
susceptibility to low-dominant intrusions in Experiment 4, which again is arguably a consequence of poorer distraction inhibition.

However, although inhibition may be operable within the current study, the results also show that it is not the only mechanism underpinning the betweensequence semantic similarity effect, since the between-sequence semantic similarity effect and NP sometimes appear unrelated to one another. The findings reported here, however, are consistent with those of many other studies that have failed to find a correlation between the magnitude of a concurrent distraction and the magnitude of NP (e.g., Driver \& Tipper, 1989; Stolzfus, Hasher, Zacks, Ulivi, \& Goldstein, 1993). One possibility why NP and the between-sequence semantic similarity effect are not always related is that the between-sequence semantic similarity effect is a composite of at least two mechanisms: The competition itself (if it is not inhibited) and an overhead-of-successful-inhibition of the competition. High-WMC individuals resolve the competition through more successful inhibition of distracters, but have to pay the cost of this inhibition - as revealed by the NP effect. Low-WMC individuals, in contrast, are less successful in inhibiting the competition. Failure-to-inhibit the competition — which impacts on low-WMC individuals in particular-could result in blocking of the retrieval access for targets (Anderson, 1983; Mensink \& Raaijmakers, 1988; Rundus, 1973).

Of interest, WMC predicts the appearance of intrusion errors regardless of whether they are presented synchronously (Experiments 1-4) or asynchronously (Experiment 1) with the target words or during a retention interval (Beaman, 2004). The requirement for such selection processes are clearly accentuated when target and distracters are presented synchronously and hence are simultaneously activated. On an inhibition selection view, distracter inhibition during the selection process at study 
may prevent the distracters from being fully encoded, thus preventing them from coming to mind during test (constraints on access). An alternative view is that selection processes have an influence at test by, for example, isolating the distracter from the temporal context of the target list during recall (i.e., output-monitoring), either of which would have a direct impact upon correct recall. The dissociation between constraints on access and monitoring at output fits with the distinction between "back-end" and "front-end" monitoring processes.

Back-end control mechanisms such as the distinctiveness heuristic (Dodson \& Schacter, 2002) or recollection rejection (Brainerd, Reyna, Wright, \& Mojardin, 2003) operate subsequent to (covert) retrieval but before output to assess the appropriateness of outputting a given item (e.g., Halamish, Goldsmith, \& Jacoby, 2012). Once (covertly) retrieved, an item —or its associated features - is evaluated to determine whether it can be positively identified as a target or an intrusion (e.g., an item presented as a distracter; Budson et al., 2005). Recent evidence suggests that discriminatory cues may be used at retrieval when under distraction because varying the physical similarity between distracters and targets affected the appearance of both false and correct recalls in a semantic distraction task (Beaman, Hanczakowski, Hodgetts, Marsh, \& Jones, 2013). On the other hand, front-end control mechanisms operate by focussing retrieval such that it is mainly information from the desired source that comes to mind during test (e.g., Jacoby et al., 2005). Front-end control mechanisms, therefore, have a similar action to inhibitory mechanisms which prevent the erroneous encoding of distracters such that they do not come to mind during test. We suggest that the synchronicity manipulation of Experiment 1 affects front-end control, with lower WMC participants being unable to prevent related distracters from being processed when in phase with distracters (cf. Sörqvist et al., 2010b). 
The results of our Experiment 1 are also consistent with recent evidence (Marsh, Sörqvist, \& Hughes, 2013) suggesting that externally-induced taskengagement (overlaying targets with visual noise; cf. Hughes et al., 2013) can reduce the intrusiveness of distracters whilst, crucially, leaving the number of control intrusions (that were not part of the speech stream and therefore internal-external source-monitoring errors) unaffected (see also Halin, Marsh, Haga, Holmgren, \& Sörqvist, 2014). Moreover, when participants were instructed to use inclusion recall whereby they are instructed to recall any visual targets and any other related items that came to mind during test (Hege \& Dodson, 2004; Hunt et al., 2011), more intrusions were generated overall but the same pattern emerged: Fewer distracters were generated in the high task-engagement condition. Since output-monitoring is disengaged with inclusion recall, these data indicate that the task-engagement manipulation benefitted front-end monitoring. Therefore, it appears that when the system is more readily engaged by the focal task (via encoding the target), distracter items are more readily suppressed, at least amongst individuals with high WMC. Perhaps the key concept here, with regard to the modulation of distraction, is whether there is top-down, moment-to-moment control of the amount of task-engagement. Consistent with this notion, low WMC participants typically benefit from taskengagement manipulations whereas high WMC participants do not (Halin, Marsh, Hellman, Hellström, \& Sörqvist, 2014).

\section{Alternative accounts}

Although the suggestion that our results reflect inhibition is consonant with earlier theorizing (Marsh et al., 2012) and the experimental predictions within this series were originally made on this assumption, alternative non-inhibitory accounts of 
the results may be possible. One candidate hypothesis is that the NP effect is underpinned in part by source confusion. Within our study, NP is indexed by poorer recall performance for items ignored in the context of a preceding prime trial and completely novel words that were not presented in that earlier context. That the items on the ignored repetition probe trials have two contexts associated with them - being experienced on the preceding prime trial as distracters and then as novel words during the probe trial - could create a source confusion and/or response output bias ${ }^{2}$. For example, retrieval of an item on the ignored repetition probe trial may carry with it source modality information that would identify the item as a distracter on the previous prime trial. Unless participants become aware that all of the distracters presented at prime are thereafter presented in the ignored repetition probe trials, they could withhold these items. Such response-withholding would only operate during the ignored repetition probe trials since the distracters presented during prime in the control probe trials are never presented as targets. Data from metacognitive studies show that reduced levels of confidence - and a concomitant reduction in the number of freely offered responses - are a feature of auditory distraction (Beaman et al., 2014). However, two lines of evidence appear to rule out an explanation based on source confusion. First, low output-dominant items experienced as distracters at prime are better remembered during the ignored repetition condition than items experienced for the first time at probe (see Experiment 4 within the current paper and Experiment 2 within Marsh et al., 2012) despite the fact that the low-dominant items have two contexts associated with them. Second, distracters that are categorically-unrelated to the items experienced at prime, enjoy facilitation in recall during the ignored repetition probe trials (see Marsh et al., 2012, Experiment 3). Again, these items are associated in two contexts and could, feasibly, create source-monitoring difficulties. 
Similarly, an alternative explanation for the apparent WMC differences is that high WMC individuals are superior at monitoring their output at test recognizing that, in fact, some of the items that they generate are intrusions. For example, Unsworth and Brewer (2010b) in the context of an output-editing task-whereby participants are encouraged to speak aloud any items that come to mind during test—found that individuals with high, as compared with low, WMC were better at monitoring their output; indeed, although high and low-WMC participants produced a comparable number of intrusions, high-WMC participants were more frequently able to indicate that the false recalls they generated were intrusion errors. The enigma here is that if high-WMC individuals are better at inhibiting semantically related items at the front end - as the inhibition view suggests - then low-WMC individuals should generate more intrusions than high-WMC individuals during test regardless of whether those items are covertly generated or overtly produced (as is the case with the outputediting technique).

With these details in mind, could the results of our current study be attributable to differences in output-monitoring? Perhaps the most problematic finding yet to be accounted for within this perspective is the consistent correlation between WMC and the NP magnitude whereby high-WMC individuals are more susceptible to the NP effect. Under the assumption that NP reflects a failure of source/outputmonitoring, we might conclude that high-WMC individuals have poorer source/output-monitoring abilities, which is in direct contradiction to the findings of Unsworth and Brewer (2010b). It is simpler, perhaps, to conclude that high-WMC individuals engage more effectively with distracters, rendering them more vulnerable to interference from other sources. For example, Hanczakowski et al. (2014) suggest that NP as defined here may be a form of proactive interference rather than a 
consequence of inhibition per se. As such, one would ordinarily expect a negative relationship with WMC (e.g., Kane \& Engle, 2000; Rosen \& Engle, 1998) rather than the positive relationship observed here, and in our analysis of prior-list intrusions within the control probe condition-not contaminated by the presence of related distracters at prime — we also found that low WMC participants were more susceptible to prior-list intrusions (Experiments 2 and 4). It is possible that the more effective deployment of resources to resist auditory distraction shown by high-WMC individuals elsewhere in this series might reverse this usual relationship; there is precedent for semantic auditory distraction removing - if not reversing - otherwise reliable interference effects (e.g., retrieval-induced forgetting; Marsh, Sörqvist, Beaman \& Jones, 2013).

\section{Conclusions}

In sum, this paper has illuminated how the human selective attention system strikes a healthy balance between the engageability and flexibility of selectivity (Allport, 1993) by scrutinising further the way in which the obligatory processing of irrelevant auditory information disrupts the free recall of semantic information (Beaman, 2004; Neely \& LeCompte, 1999; Marsh et al., 2008). Moreover, we have shown that the cognitive control mechanism - be it inhibition or no - that responds to unwanted competition from related memories, carries a negative consequence for the later recall of the competing, non-target, memories, particularly so for more cognitively capable individuals. However, without such control the effects of distraction can be even greater. Therefore, the price of cognitive control is one worth paying given that the potential gain to the system from preventing distraction outweighs the cost. 


\section{References}

Allport, D. A. (1993). Attention and control: Have we been asking the wrong questions? A critical review of 25 years. In D. E. Meyer \& S. Kornblum (Eds.), Attention and performance XIV (pp. 183-218). Cambridge, MA: MIT Press.

Anderson, J. R. (1983). The Architecture of Cognition. Cambridge MA: Harvard University Press.

Anderson, M. C., Bjork, R. A., \& Bjork, E. L. (1994). Remembering can cause forgetting: Retrieval dynamics in long-term memory. Journal of Experimental Psychology: Learning, Memory, and Cognition, 20, 1063-1087.

Anderson, M. C., Green, C., \& McCulloch, K. C. (2000). Similarity and inhibition in long-term memory: Evidence for a two-factor theory. Journal of Experimental Psychology: Learning, Memory, \& Cognition, 26, 1141-1159.

Anderson, M. C., \& Neely, J. H. (1996). Interference and inhibition in memory retrieval. In E. L. Bjork \& R. A. Bjork (Eds.), Memory: Handbook of perception and cognition ( $2^{\text {nd }}$ ed.; pp. 237-313). San Diego: Academic Press.

Anderson, M. C., \& Spellman, B. A. (1995). On the status of inhibitory mechanisms in cognition: Memory retrieval as a model case. Psychological Review, 102, $68-100$.

Aslan, A., \& Bäuml, K.-H. T. (2011). Individual differences in working memory capacity predict retrieval-induced forgetting. Journal of Experimental Psychology: Learning, Memory, \& Cognition, 37, 264-269.

Beaman, C. P. (2004). The irrelevant sound phenomenon revisited: What role for working memory capacity? Journal of Experimental Psychology: Learning, Memory, \& Cognition, 30, 1106-1118. 
Beaman, C. P., Bridges, A. M., \& Scott, S. K. (2007). From dichotic listening to the irrelevant sound effect: A behavioural and neuroimaging analysis of the processing of unattended speech. Cortex, 43, 124-134

Beaman C. P., Hanczakowski, M., \& Jones, D. M. (2014). The effects of distraction on metacognition and metacognition on distraction: Evidence from recognition memory. Frontiers in Psychology.

Beaman, C. P., Hanczakowski, M., Hodgetts, H. M., Marsh, J. E., \& Jones, D. M. (2013). Memory as discrimination: What distraction reveals. Memory \& Cognition, 41, 1238-1251.

Bell, R., Buchner, A., \& Mund, I. (2008). Age-related differences in irrelevant-speech effects. Psychology \& Aging, 23, 377-391.

Buchner, A., Irmen, I., \& Erdfelder, E. (1996). On the irrelevance of semantic information for the irrelevant speech effect. Quarterly Journal of Experimental Psychology, 49A, 765-779.

Budson, A. E., Droller, D. B. J., Dodson, C. S., Schacter, D. L., Rugg, M. D., Holcomb, P. J., \& Daffner, K. R. (2005). Electrophysiological dissociation of picture versus word encoding: The distinctiveness heuristic as a retrieval orientation. Journal of Cognitive Neuroscience, 17, 1181-1193.

Conway, A. R. A., Cowan, N., \& Bunting, M. F. (2001). The cocktail party phenomenon revisited: The importance of working memory capacity. Psychonomic Bulletin \& Review, 8, 331-335.

Conway, A. R. A., Tuholski, S. W., Shisler, R. J., \& Engle, R. W. (1999). The effect of memory load on negative priming: An individual differences investigation. Memory \& Cognition, 27, 1042-1050.

de Fockert, J. W., Mizon, G. A., \& D'Ubaldo, M. (2010). No negative priming 
without cognitive control. Journal of Experimental Psychology: Human Perception and Performance, 36, 1333-1341.

Driver, J., \& Tipper, S. P. (1989). On the nonselectivity of 'selective' seeing: Contrasts between interference and priming in selective attention. Journal of Experimental Psychology: Human Perception and Performance, 15, 304314.

Elliott, E. M, Cowan, N., \& Valle-Inclan, F. (1998). The nature of cross-modal colour-word interference effects. Attention, Perception, \& Psychophysics, 60, 761-767.

Engle, R. W. (2002). Working memory capacity as executive attention. Current Directions in Psychological Science, 11, 19-23.

Fox, E. (1996). Cross-language priming from ignored words: Evidence for a common representational system in bilinguals. Journal of Memory and Language, 35, 353-370.

Frings, C., \& Wentura, D. (2006). Negative priming is stronger for task-relevant dimensions: Evidence of flexibility in the selective ignoring of distractor information. Quarterly Journal of Experimental Psychology, 59, 683-689.

Gunter, T. C., Wagner, S., \& Friederici, A. D. (2003). Working memory and lexical ambiguity resolution as revealed by ERPs: A difficult case for activation theories. Journal of Cognitive Neuroscience, 15, 643-567.

Halamish, V., Goldsmith, M., \& Jacoby, L. L. (2012). Source-constrained recall: Front-end and back-end control of retrieval quality. Journal of Experimental Psychology: Learning, Memory, and Cognition, 38, 1-15. 
Halin, N., Marsh, J. E., Haga, A., Holmgren, M., \& Sörqvist, P. (2014). Effects of speech on proofreading: Can task-engagement manipulations shield against distraction? Journal of Experimental Psychology: Applied, 20, 69-80.

Halin, N., Marsh, J. E., Hellman, A., Hellström, I., \& Sörqvist, P. (2014). A shield against distraction. Journal of Applied Research in Memory \& Cognition, 3, $31-36$.

Hamilton, A. C., \& Martin, R. C. (2007). Proactive interference in a semantic shortterm memory deficit: role of semantic and phonological relatedness. Cortex, $43,112-123$.

Hanczakowski, M., Beaman, C. P., \& Jones, D. M. (2014). Negative priming in free recall: What role for inhibition? Manuscript submitted for publication.

Hasher, L., Zacks, R. T., \& May, C. P. (1999). Inhibitory control, circadian arousal, and age. In D. Gopher \& A. Koriat (Vol. Eds.), Attention and performance: XVII. Cognitive regulation of performance: Interaction of theory and application (pp. 653-675). Cambridge MA: MIT Press.

Hege, A. C. G., \& Dodson, C. S. (2004). Why distinctive information reduces false memories: Evidence for both impoverished relational encoding and distinctiveness heuristic accounts. Journal of Experimental Psychology: Learning, Memory, \& Cognition, 30, 787-795.

Heitz, R. P, Engle, R. W. (2007). Focusing the spotlight: individual differences in visual attention control. Journal of Experimental Psychology: General, $136,217-240$.

Hughes, R. W., Hurlstone, M., Marsh, J. E., Vachon, F., \& Jones, D. M. (2013). Cognitive control of auditory distraction: Impact of task difficulty, foreknowledge, and working memory capacity supports duplex-mechanism 
account. Journal of Experimental Psychology: Human Perception \& Performance, 39, 539-553.

Hughes, R. W., \& Jones, D. M. (2003). A negative order-repetition priming effect: Inhibition of order in unattended auditory sequences. Journal of Experimental Psychology. Human Perception and Performance, 29, 1, 199-218.

Hunt, R. R., Smith R. E., \& Dunlap, K. D. (2011). How does distinctive processing reduce false memory? Journal of Memory and Language, 65, 378-389.

Hutchison, K. A. (2002). The effect of asymmetrical association on positive and negative semantic priming. Memory \& Cognition, 30, 1263-1276.

Hutchinson, K. A. (2011). The interactive effects of listwide control, item-based control, and working memory capacity on Stroop performance. Journal of Experimental Psychology: Learning, Memory, \& Cognition, 33, 645-662.

Jacoby, L. L., Wahlheim, C. N., Rhodes, M. G., Daniels, K. A., \& Rogers, C. S. (2010). Learning to diminish the effects of proactive interference: Reducing false memory for young and older adults. Memory \& Cognition, 38, 820-829.

Jones, D. M., Marsh, J. E. \& Hughes, R. W. (2012). Retrieval from memory: Vulnerable or inviolable? Journal of Experimental Psychology: Learning, Memory, \& Cognition, 38, 905-922.

Kane, M. J., \& Engle, R. W. (2000). Working memory capacity, proactive interference, and divided attention: Limits on long-term memory retrieval. Journal of Experimental Psychology: Learning, Memory, \& Cognition, 26, 333-358.

Kane, M. J., \& Engle, R. W. (2003). Working-memory capacity and the control of attention: The contributions of goal neglect, response competition, and task-set to Stroop interference. Journal of Experimental Psychology: General, 132, 47- 
70.

Kiang, M., \& Kutas, M. (2006). Abnormal typicality of responses on a category fluency task in schizotypy. Psychiatry Research, 145, 119-126.

Kimball, D. R., \& Bjork, R. A. (2002). Influences of intentional and unintentional forgetting on false memories. Journal of Experimental Psychology: General, $131,116-130$.

Long, D. L., \& Prat, C. S. (2002). Working memory and Stroop interference: An individual differences investigation. Memory \& Cognition, 30, 294-301.

Mall J. T., \& Morey, C. C. (2013). High working memory capacity predicts less retrieval induced forgetting. PLoS ONE, 8, e52806.

MacLeod, M.D. \& Saunders, J. (2008). Negative consequences of an adaptive process: Retrieval inhibition and memory distortion. Current Directions in Psychological Science, 17, 26-30.

Marsh, J. E., Beaman, C. P., Hughes, R. W., \& Jones, D. M. (2012). Inhibitory control in memory: Evidence for negative priming in free recall. Journal of Experimental Psychology: Learning, Memory \& Cognition, 38, 1377-88.

Marsh, J. E., Hughes, R. W., \& Jones, D. M. (2008). Auditory distraction in semantic memory: A process-based approach. Journal of Memory \& Language, 58, $682-700$.

Marsh, J. E., Hughes, R. W., \& Jones, D. M. (2009). Interference by process, not content, determines semantic auditory distraction. Cognition, 110, 23-38.

Marsh, J. E., \& Jones, D. M. (2010). Cross-modal distraction by background speech: What role for meaning? Noise \& Health, 12, 210-216.

Marsh, J. E., Pilgrim, L. K., \& Sörqvist, P. (2013). Hemispheric specialisation in selective attention and short-term memory: A fine-coarse model of left and 
right ear disadvantages. Frontiers in Psychology, 4, 976.

Marsh, J. E., Sörqvist, P., Beaman, C. P., \& Jones, D. M. (2013). Auditory distraction eliminates retrieval-induced forgetting: Implications for the processing of unattended sound. Experimental Psychology, 5, 368-375.

Marsh, J. E., Sörqvist, P., \& Hughes, R. W. (2013). Cognitive control of distraction: How does task-engagement modulate the effects of between-sequence semantic similarity? Paper presented at the 54th annual meeting of the Psychonomic Society, Toronto, ON, Canada.

Marsh, J. E., Vachon, F., \& Jones, D. M. (2008). When does between-sequence phonological similarity produce irrelevant sound disruption? Journal of Experimental Psychology: Learning, Memory, \& Cognition, 34, 243-248.

Meng, X., Rosenthal, R., \& Rubin, D. B. (1992). Comparing correlated correlation coefficients. Psychological Bulletin, 111, 172-175.

Mensink, J. G., \& Raaijmakers, J. G. W. (1988). A model of interference and forgetting. Psychological Review, 95, 434-455.

Neely, C. B., \& LeCompte, D. C. (1999). The importance of semantic similarity to the irrelevant speech effect. Memory \& Cognition, 27, 37-44.

Neumann, E., Cherau, J. F., Hood, K. L., \& Steinnagel, S. L. (1993). Does inhibition spread in a manner analogous to spreading activation? Memory, 1, 81-105.

Neumann, E., \& DeSchepper, B. G. (1992). An inhibition-based fan effect: Evidence for an active suppression mechanism in selective attention. Canadian Journal of Experimental Psychology, 46, 1-40.

Ortells, J. J., Abad, M. J. F., Noguera, C., \& Lupiáñez, J. (2001). Influence of prime-probe stimulus onset asynchrony and prime precuing manipulations on semantic priming effects with words in a lexical-decision task. Journal of Experimental Psychology: Human Perception and Performance, 27, 75-91. 
Raaijmakers, J. G. W., \& Jaklab, E. (2012). Retrieval-induced forgetting without competition: Testing the retrieval specificity assumption of the inhibitory theory. Memory \& Cognition, 40, 19-27.

Redick, T. S., Heitz, R. P., \& Engle, R. W. (2007). Working memory capacity and inhibition: Cognitive and social consequences. In D. S. Gorfein, \& C. M. MacLeod (Eds.), Inhibition in cognition (pp. 125-142). Washington, DC: American Psychological Association.

Rosen, V. M., \& Engle, R. W. (1997). The role of working memory capacity in retrieval. Journal of Experimental Psychology: General, 126, 211-227.

Rosen, V. M., \& Engle, R. W. (1998). Working memory capacity and suppression. Journal of Memory and Language, 39, 418-436.

Rundus, D. (1973). Negative effects of using list items as retrieval cues. Journal of Verbal Learning and Verbal Behavior, 12, 43-50.

Salamé, P., \& Baddeley, A. D. (1982). Disruption of short-term memory by unattended speech: Implications for the structure of working memory. Journal of Verbal Learning \& Verbal Behavior, 21, 150-164.

Schacter, D. L., Israel, L., \& Racine, C. (1999). Suppressing false recognition in younger and older adults: The distinctiveness heuristic. Journal of Memory and Language, 40, 1-24.

Smith, R. E., \& Engle, R. W. (2011). Study modality and false recall: The influence of resource availability. Experimental Psychology, 58, 117-124.

Sörqvist, P. (2010a). The role of working memory capacity in auditory distraction: A review. Noise \& Health, 12, 217-224.

Sörqvist, P. (2010b). High working memory capacity attenuates the deviation effect but not the changing-state effect: Further support for the duplex- 
mechanism account of auditory distraction. Memory \& Cognition, 38, 651658.

Sörqvist, P., Ljungberg, K. J. Ljung, R. (2010a). A sub-process view of working memory capacity: Evidence from effects of speech on prose memory. Memory, 18, 310-326.

Sörqvist, P., Marsh, J. E., \& Jahncke, H. (2010b). Hemispheric asymmetries in auditory distraction. Brain \& Cognition, 74, 79-87.

Sörqvist, P., Marsh, J. E., \& Nöstl, A. (2013). High working memory capacity does not always attenuate distraction: Bayesian evidence in support of the null hypothesis. Psychonomic Bulletin and Review, 20, 897-904.

Sörqvist, P., Nöstl, A., \& Halin, N. (2012a). Working memory capacity modulates habituation rate: Evidence from a cross-modal auditory distraction paradigm. Psychonomic Bulletin \& Review, 19, 245-259.

Sörqvist, P., Nöstl, A., \& Halin, N. (2012b). Disruption of writing processes by the semanticity of background speech. Scandinavian Journal of Psychology, 53, 97-102.

Sörqvist, P., Stenfelt, S., \& Rönnberg, J. (2012). Working memory capacity and visual-verbal cognitive load modulate auditory-sensory gating: Toward a unified view of attention. Journal of Cognitive Neuroscience, 24, 2147-2154.

Stoltzfus, E. R., Hasher, L., Zacks, R. T., Ulivi, M., \& Goldstein, D. (1993). Investigations of inhibition and interference in younger and older adults. Journal of Gerontology: Psychological Sciences, 48, 179-188.

Tipper, S. P. (1992). Selection for action: The role of inhibitory mechanisms. Current Directions in Psychological Science, 1, 105-109. 
Tsuchida, Y., Kayayama, J., \& Murohashi, H. (2012). Working memory capacity affects the interference control of distractors at auditory gating. Neuroscience Letters, 515, 62-66.

Turner, M. L., \& Engle, R. W. (1989). Is working memory capacity task dependent? Journal of Memory \& Language, 28, 127-154.

Unsworth, N., \& Brewer, G. A. (2010a). Individual differences in false recall: A latent variable analysis. Journal of Memory \& Language, 62, 19-34.

Unsworth, N., \& Brewer, G. A. (2010b). Variation in working memory capacity and intrusion: Differences in generation or editing? European Journal of Cognitive Psychology, 22, 990-1000.

Unsworth, N., \& Engle, R. W. (2007). The nature of individual differences in working memory capacity: Active maintenance in primary memory and controlled search from secondary memory. Psychological Review, 114, 104-132.

Unsworth, N., Heitz, R. P., Schrock, J. C., \& Engle, R. W. (2005). An automated version of the operation span task. Behavior Research Methods, 37, 498 - 505.

Van Overschelde, J., Rawson, K. A., \& Dunlosky, J. (2004). Category norms: An updated and expanded version of the Battig and Montague (1969) norms. Journal of Memory \& Language, 50, 289-335.

Watson, J. M., Bunting, M. F., Poole, B. J., \& Conway, A. R. A. (2005). Individual differences in susceptibility to false memory in the Deese-RoedigerMcDermott paradigm. Journal of Experimental Psychology: Learning, Memory, \& Cognition, 31, 76-85.

Weisz, N., \& Schlittmeier, S. J. (2006). Detrimental effects of irrelevant speech on serial recall of visual items are reflected in reduced visual $\mathrm{N} 1$ and reduced theta activity. Cerebral Cortex, 16, 1097-1105. 
Author note

John E. Marsh, School of Psychology, University of Central Lancashire, Preston, UK and the University of Gävle, Sweden. Patrik Sörqvist, University of Gävle, Sweden, Cardiff University, UK, and Linnaeus centre HEAD, Swedish Institute for Disability Research, Linköping University, Sweden. Helen M. Hodgetts, École de psychologie, Université Laval, Québec, Québec, Canada, and the Department of Applied Psychology, Cardiff Metropolitan University, Cardiff, UK. C. Philip Beaman, University of Reading, Reading, UK. Dylan M. Jones, School of Psychology, Cardiff University, UK. Dylan M. Jones is also adjunct Professor at the Department of Psychology at the University of Western Australia. The research reported in this paper was supported by an ESRC grant (RES-062-23-1752) awarded to C. Philip Beaman and Dylan M. Jones, and by a Swedish Research Council (2010-2042) ENNAH grant awarded to Patrik Sörqvist

. We thank Vicky Stenner, Sonia Packwood, Jennifer Daffin, Melissa Barker, Victoria Smith, and Zofia Mannings for help with data collection and scoring. We also thank Susanne Mayr for useful discussions concerning this manuscript. Correspondence can be addressed to John E. Marsh, University of Central Lancashire, Preston, United Kingdom. Email may be sent to jemarsh@uclan.ac.uk. 


\section{Footnotes}

${ }^{1}$ The comparison between the two correlation coefficients is calculated by taking the difference between the Fisher z-transformed coefficients and multiplying this difference with an expression that takes into consideration the number of participants and the correlation amongst the two predictor variables.

${ }^{2}$ We thank Susanne Mayr for pointing out this possibility. 
Figure captions

Figure 1. The figure shows the means for proportion correct recall (panel A) and the means for intrusions (false recall; panel B) in the four experimental conditions. Error bars are standard error of means.

Figure 2. The figure shows the relationship between the magnitude of the betweensequence semantic similarity effect and operation span scores with synchronous presentation (panel A) and with asynchronous presentation (panel B) of targets and distracters (z-values are presented for both variables).

Figure 3. The figure shows the relationship between the mean number of intrusions caused by speech (intrusions in the related target-distracter relation condition minus intrusions in the unrelated condition) and operation span scores with synchronous presentation (panel A) and with asynchronous presentation (panel B) of targets and distracters (z-values are presented for both variables).

Figure 4. Schematic of the basic experimental design. At trial $N$, visual to-be-recalled items are presented, all drawn from the same semantic category. Auditory distracter words are presented concurrently with the to-be-recalled words. The auditory words either belong to the same semantic category as the to-be-recalled words (related prime trials) or to a different category (unrelated prime trials). At trial $N+1$, no auditory items were presented. For distracter-repetition trials, visual to-be-recalled items at trial $N+1$ were identical to the auditory items from trial $N$ (semantically related to the to-be-recalled items at trial $N$ ). For control trials, the visual items at trial $N+1$ were 
from the same semantic category as visual items at trial $N$ but had not previously been presented.

Figure 5. The figure shows the relationship between the magnitude of the betweensequence semantic similarity effect and the magnitude of the negative-priming effect in Experiment 2. The data points are z-values.

Figure 6. The figure shows the relationship between the operation span (working memory capacity) scores and the magnitude of the negative priming (NP) effect in Experiment 2. Larger values on the y-axis represent larger NP effects. The data points are z-values.

Figure 7. The figure shows the relationship between the operation span (working memory capacity) scores and the magnitude of the between-sequence semantic similarity effect in Experiment 2. The data points are z-values.

Figure 8 . The figure shows the partial relationship between the magnitudes of the between-sequence semantic similarity effect and the negative priming effect in Experiment 3 wherein the variance explained by individual differences in working memory capacity has been statistically removed. The data points are z-values.

Figure 9. The figure shows the relationship in Experiment 4 between the magnitude of the between-sequence semantic similarity effect and individual differences in working memory capacity. In this case, distracters were low-output dominant and targets were high-output dominant. The data points are z-values. 
Figure 1
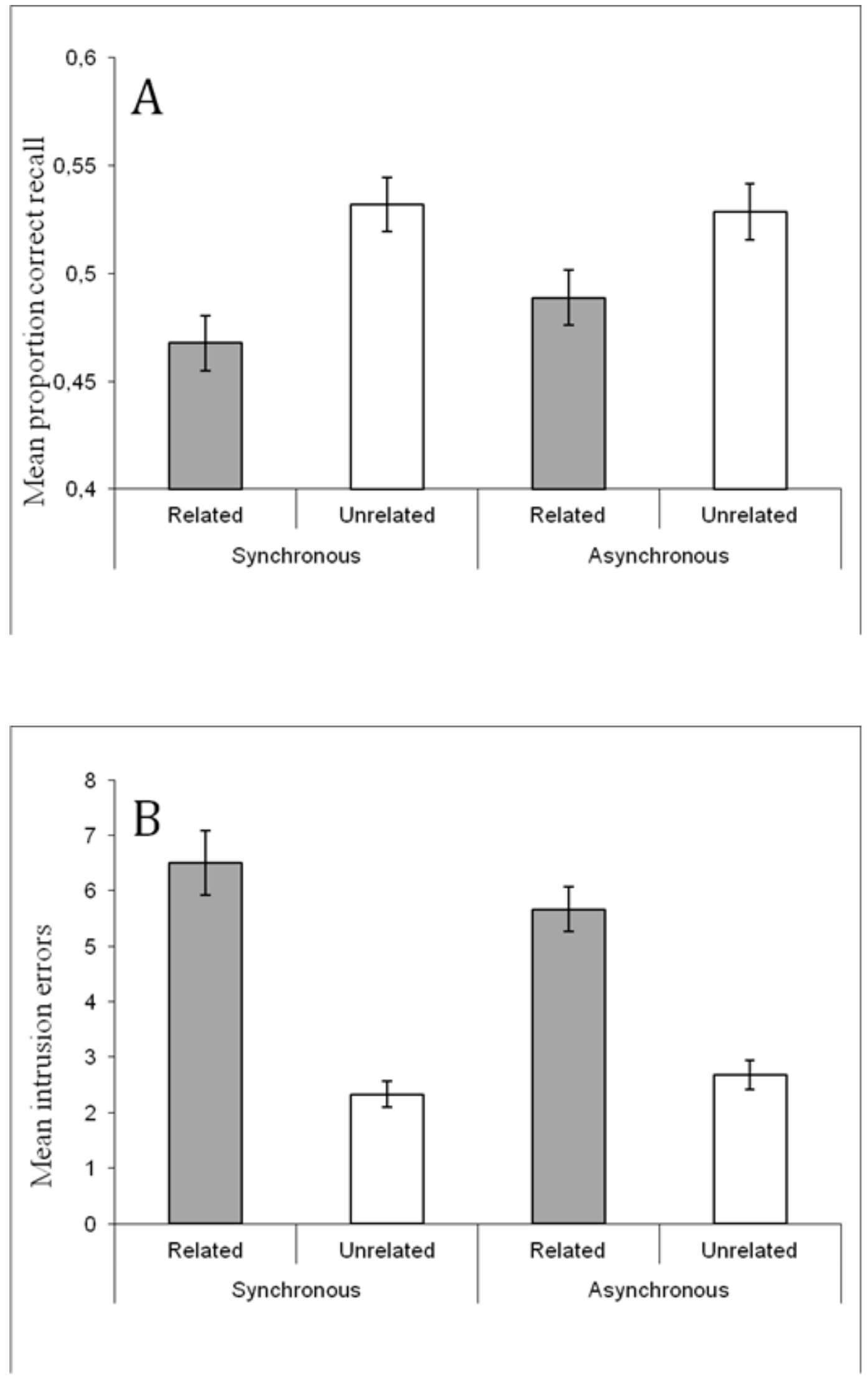
Figure 2
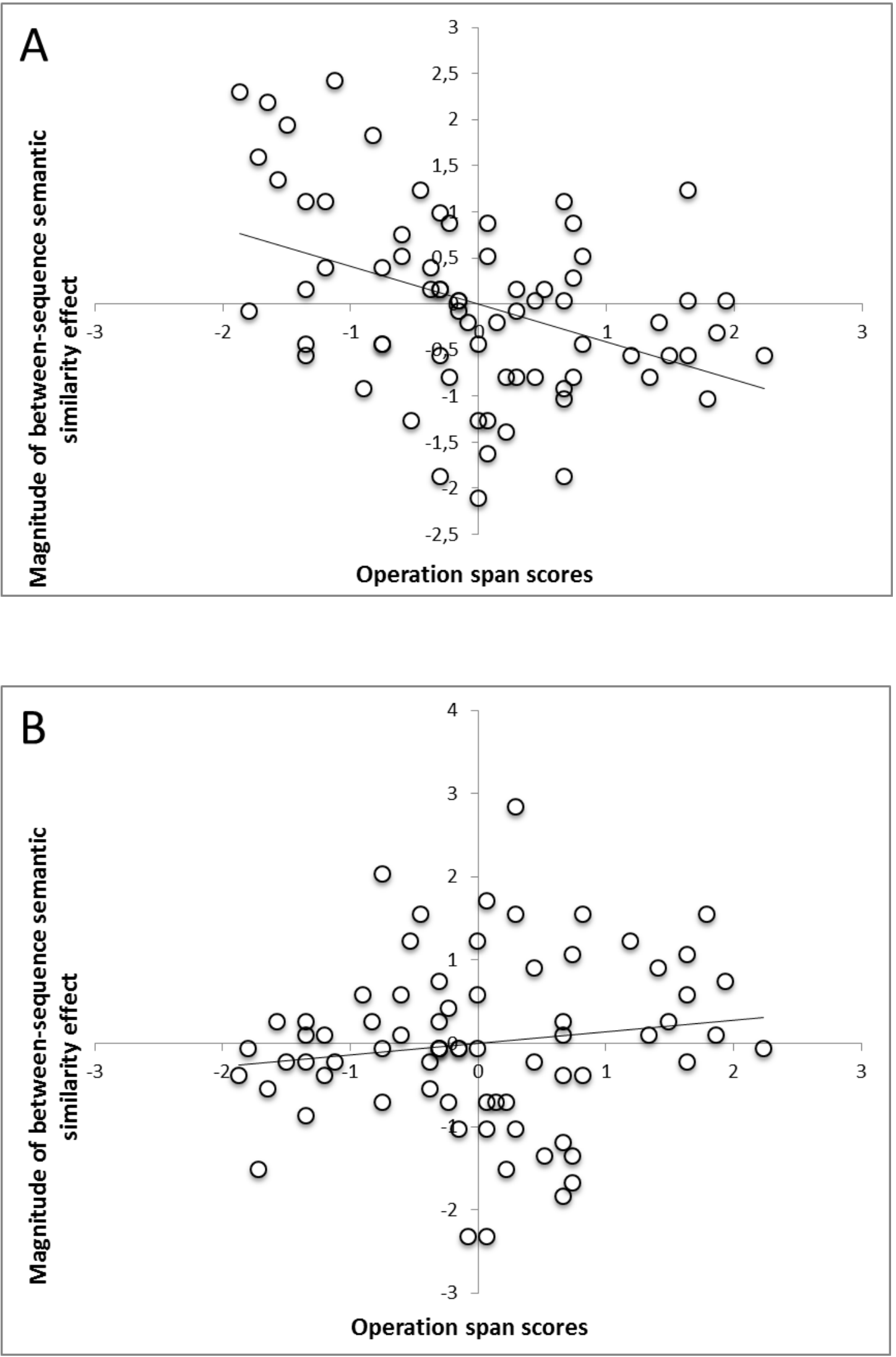
Figure 3
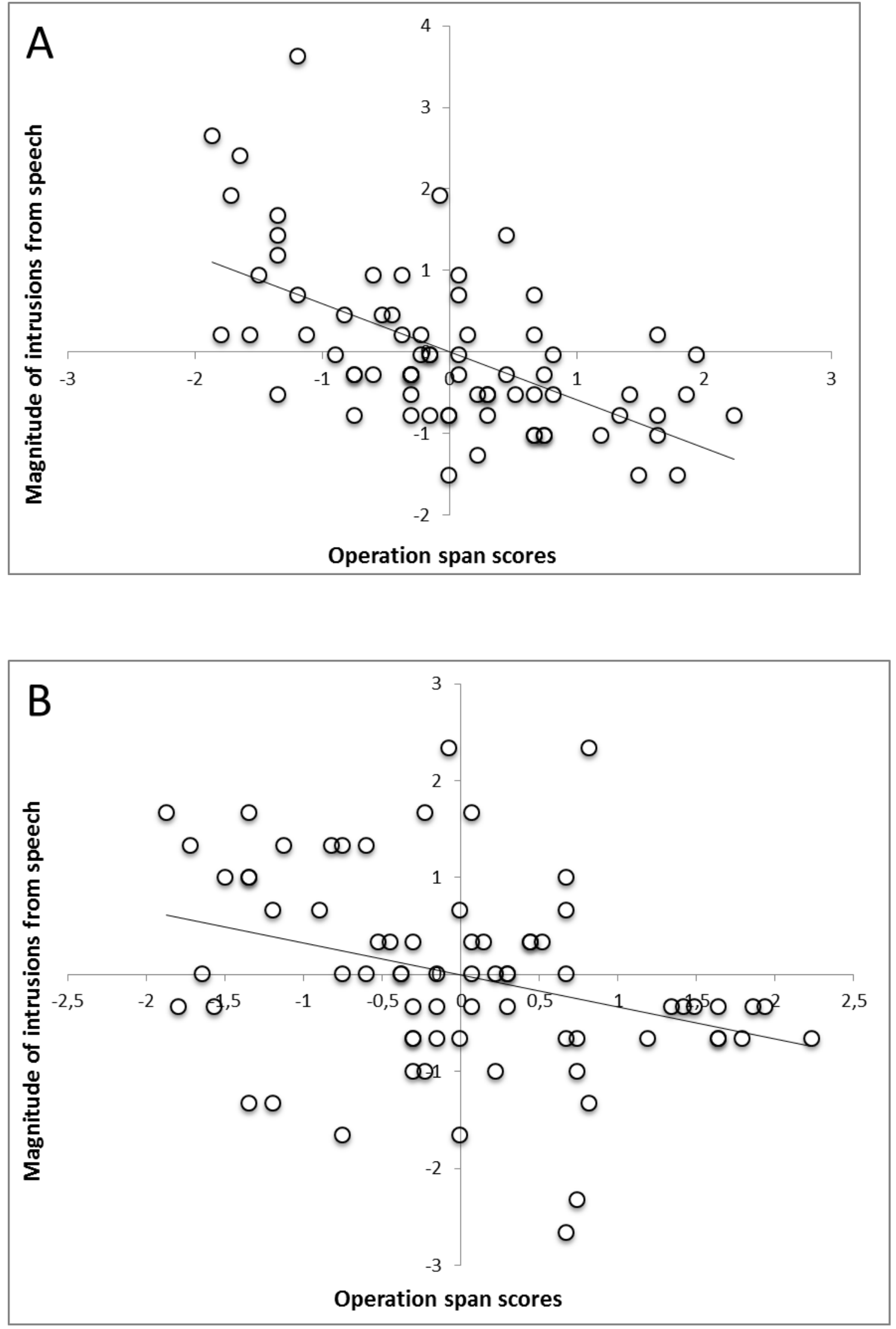
Figure 4

$\underline{\text { Trial } n \text { (prime) }}$

To-be-recalled items:

Visual presentation of 15 words drawn from the same semantic category

Auditory presentation:

15 spoken words drawn from the same category as the to-be-recalled words (related prime trial)

Or

15 spoken words drawn from a different semantic category (unrelated prime trial) $\underline{\text { Trial } n+1 \text { (probe) }}$

To-be-recalled items:

Visual presentation of the same 15 spoken distracter words that were semantically related to the to-berecalled words on trial $N$ (distracter-repetition probe trial)

Or

Visual presentation of 15 new items taken from the same category as the to-be-recalled items on trial $N$ (control condition) 
Figure 5

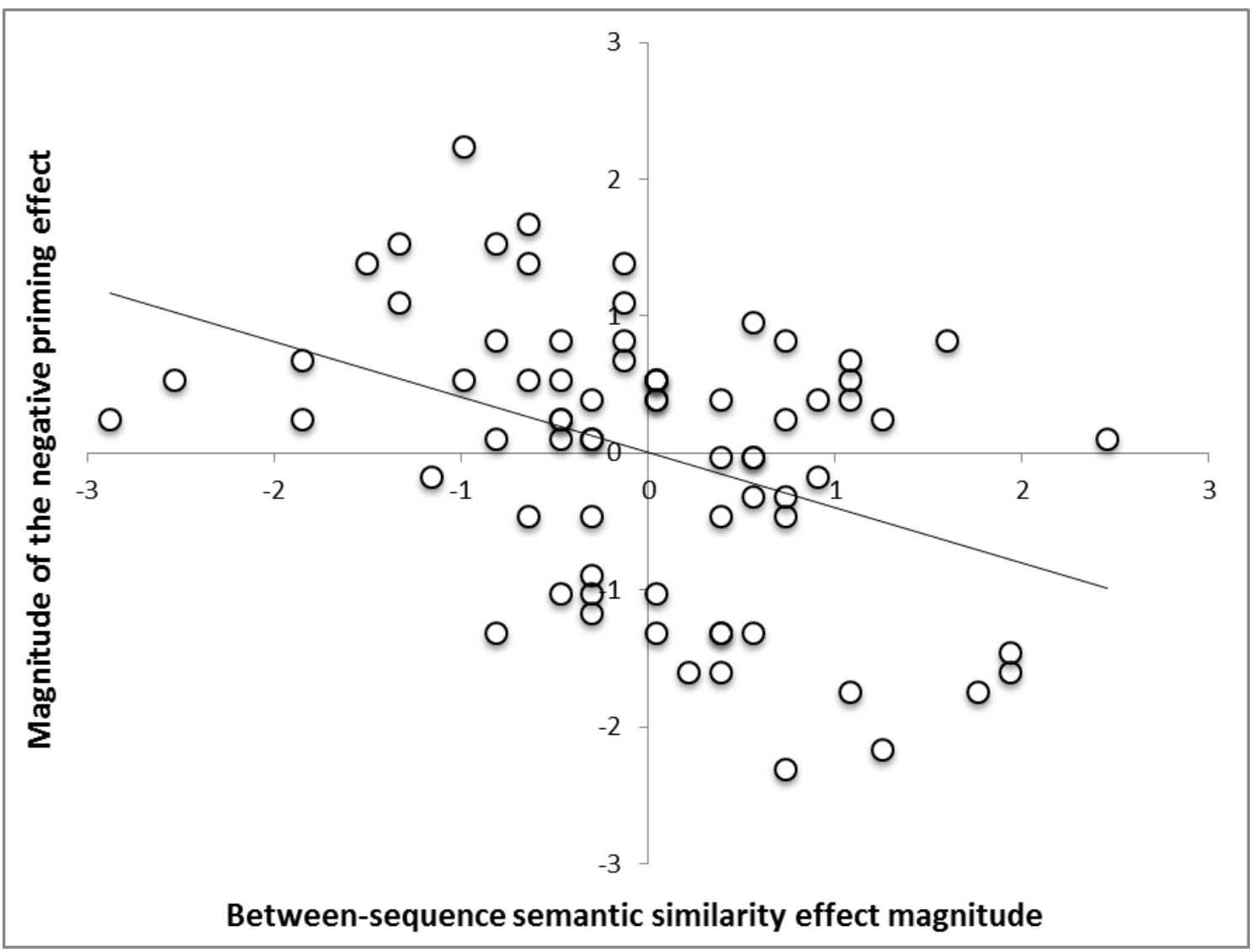


Figure 6

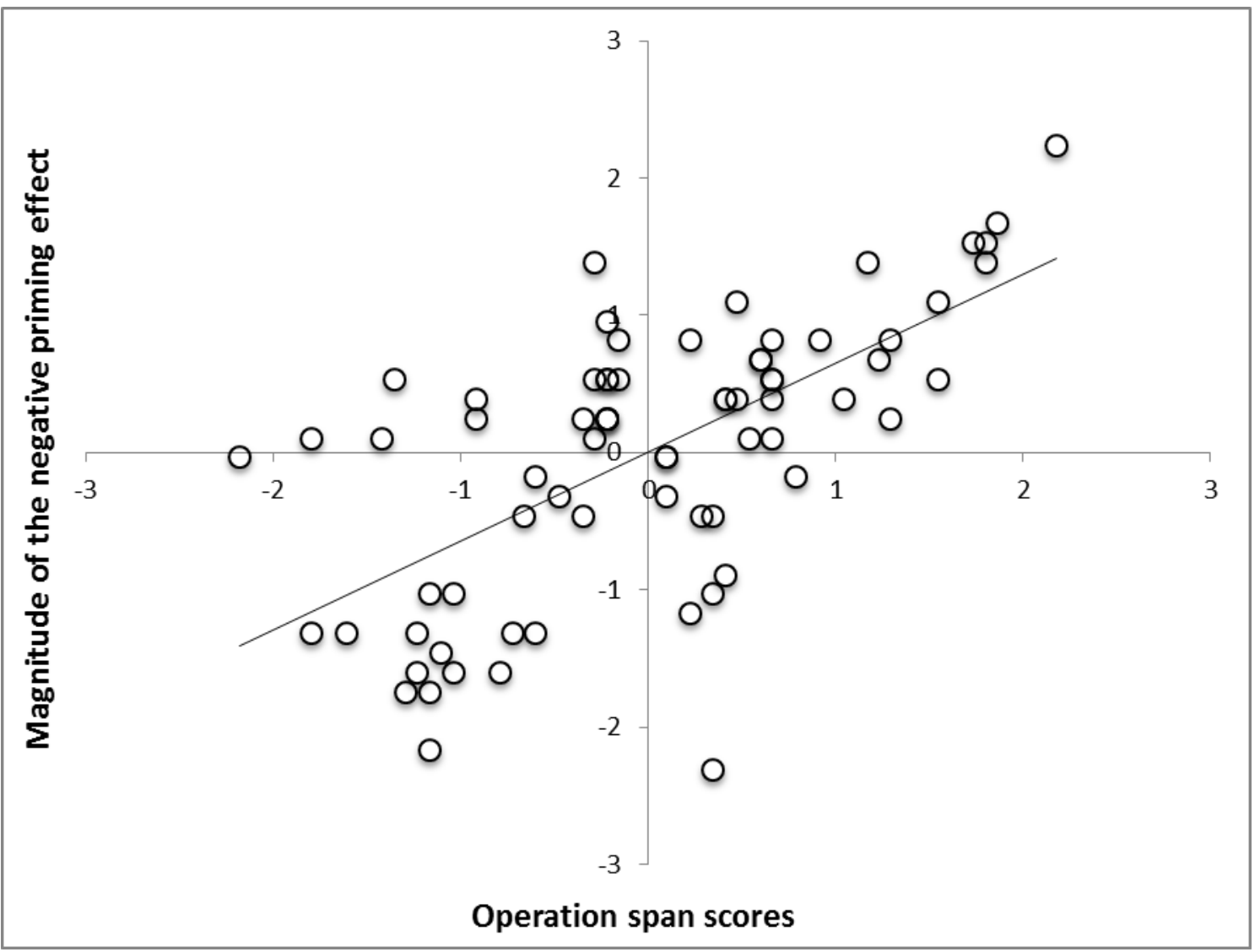


Figure 7

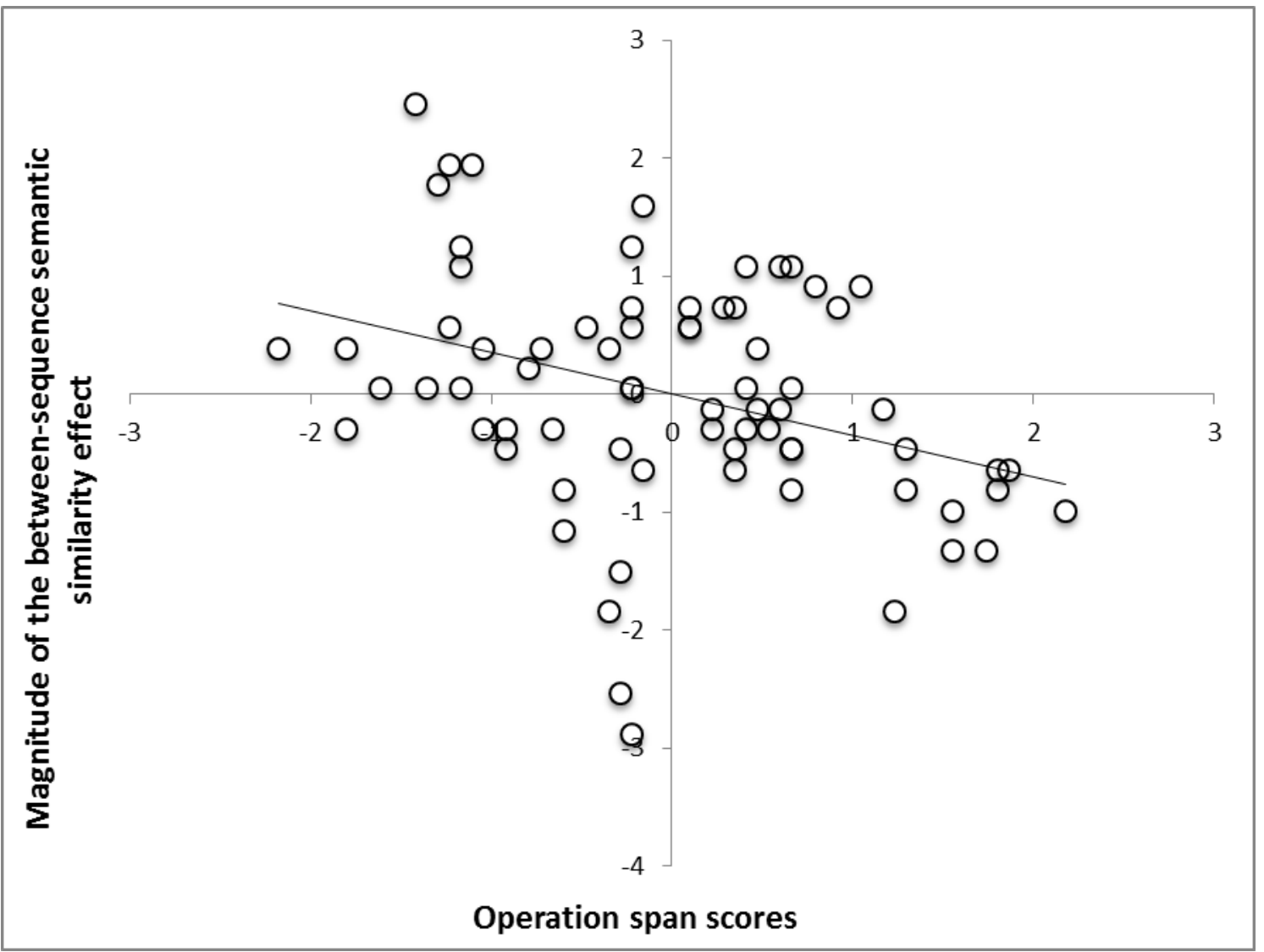


Figure 8

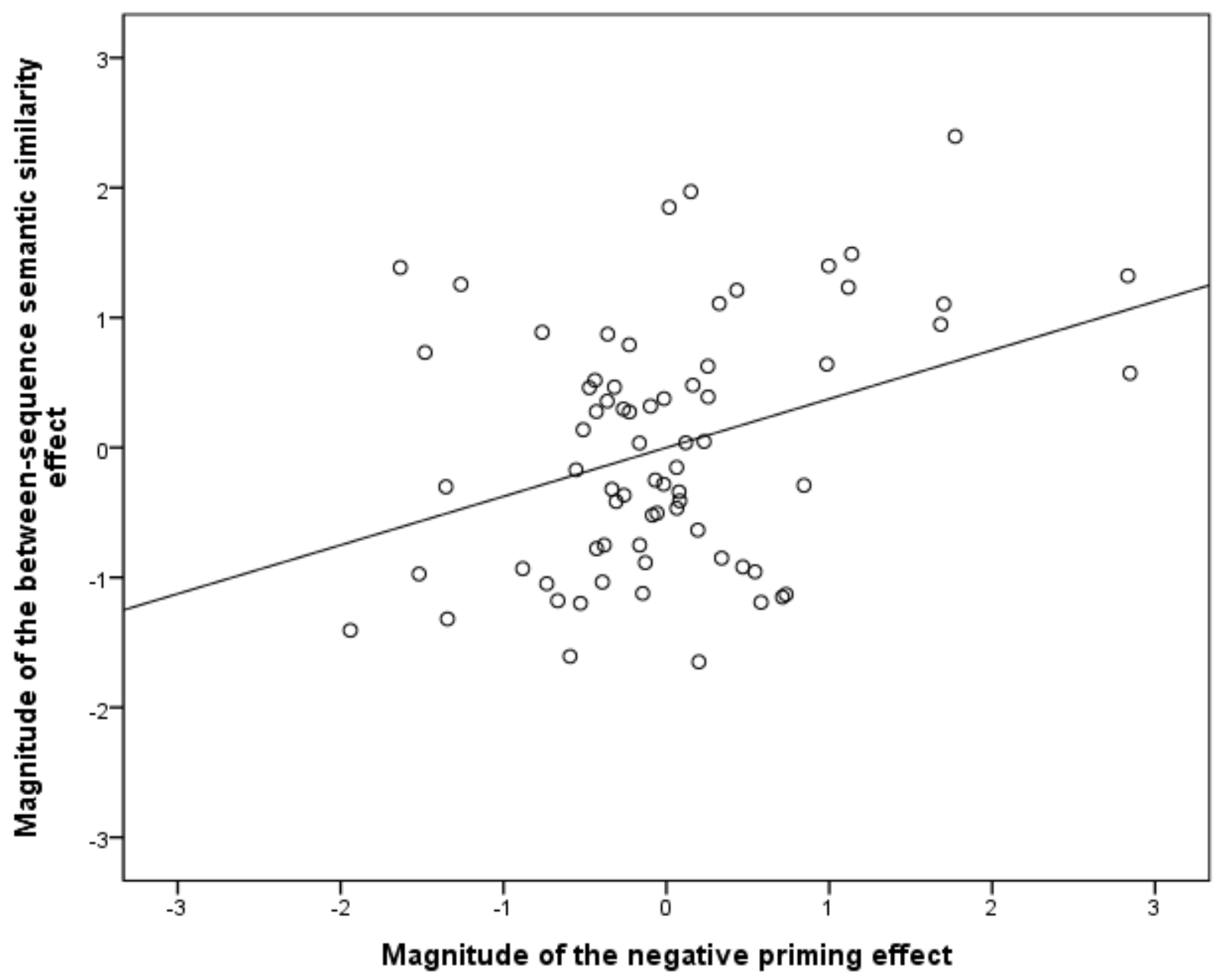


Figure 9

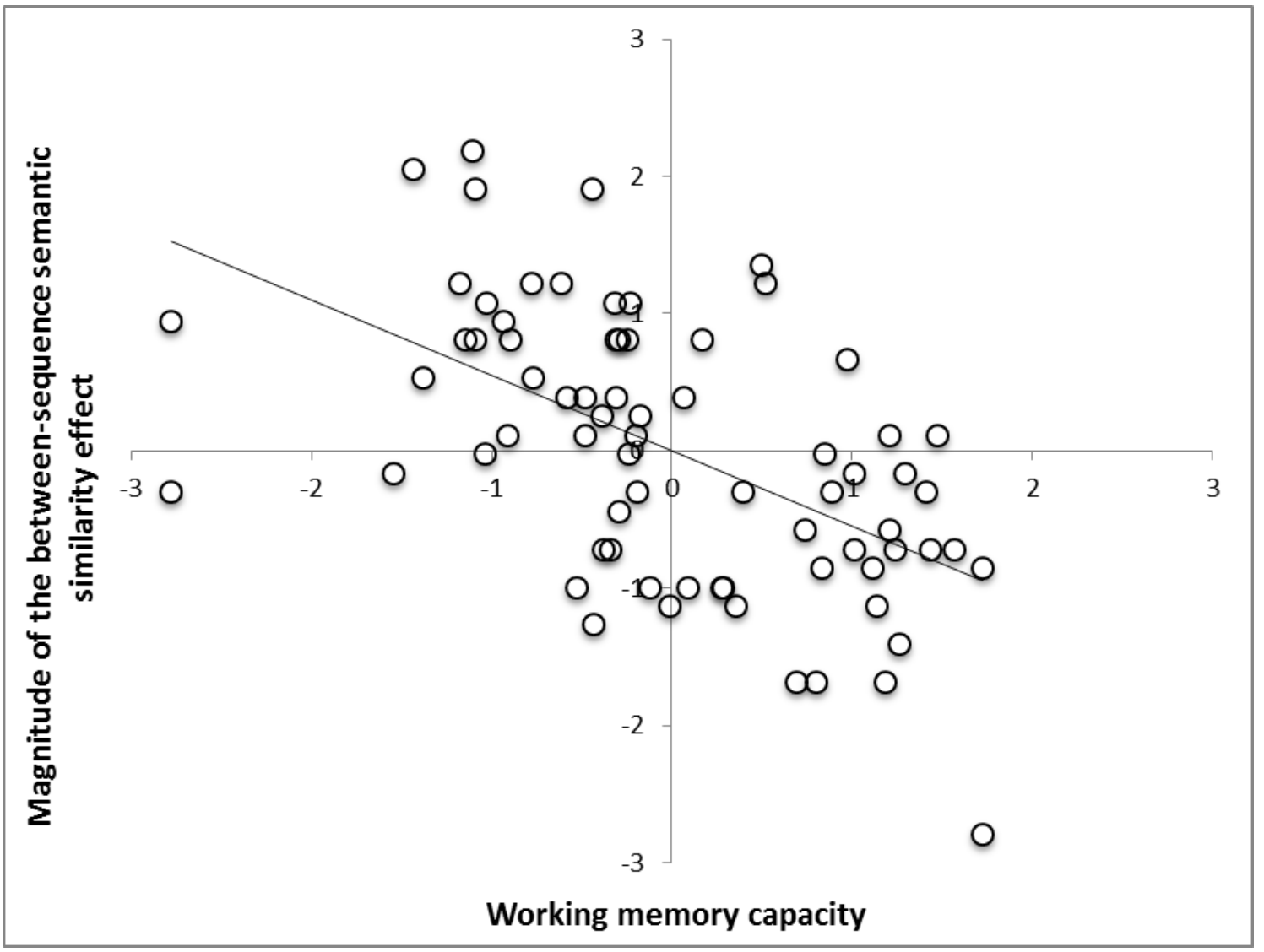


Table 1

The table shows mean correct recall for the between-sequence semantic similarity (BSSS) effect wherein the experimental condition is auditory presentation of distracters semantically-related to the to-be-recalled items, and the control condition is auditory presentation of distracters from a different category; and the negative priming (NP) effect wherein the experimental condition is recall of items at trial $\mathrm{N}+1$ that acted as distracters semantically-related to to-be-recalled items on trial N, and the control condition is recall of items at trial $\mathrm{N}+1$ that are members of the same semantic category as to-be-recalled items on trial $\mathrm{N}$ but that did not act as distracters.

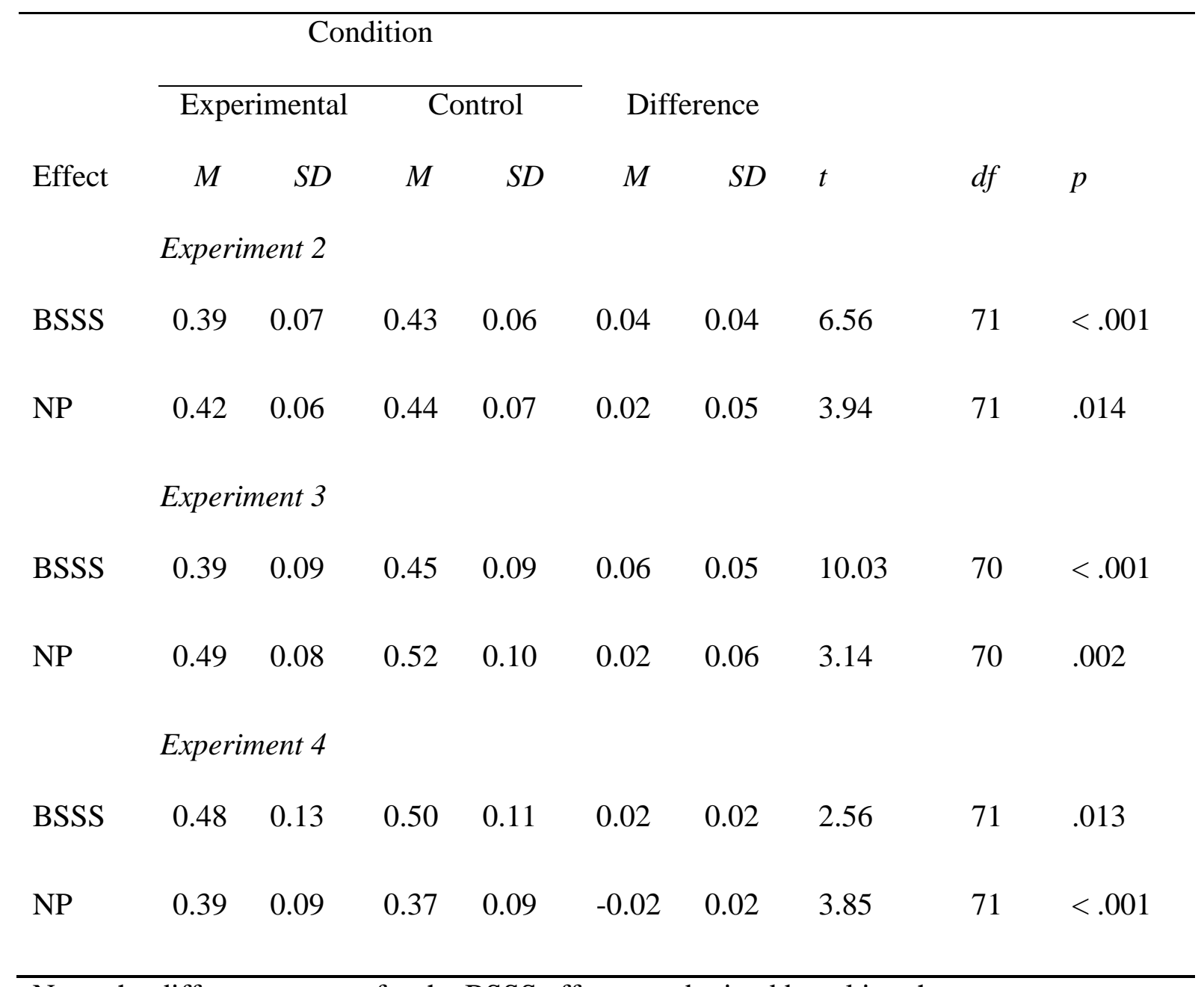

Note: the difference scores for the BSSS effect are obtained by taking the experimental condition minus the control condition, and the other way around for the 
$\mathrm{NP}$, so that positive values always represent large effects. Inferential statistic is a onesample $t$ on the difference scores with zero as comparison value. 


\section{Table 2}

The table shows mean number of distracter intrusions for the semantically-related

(Experimental) and semantically-unrelated (Control) prime trials, and prior-list intrusions for the ignored repetition (Experimental) and control probe (Control) conditions of Experiments 2-4.

\begin{tabular}{|c|c|c|c|c|c|c|c|c|c|}
\hline \multirow[b]{3}{*}{ Intrusion Type } & \multicolumn{4}{|c|}{ Condition } & & & \multirow[b]{3}{*}{$t$} & \multirow[b]{3}{*}{ df } & \multirow[b]{3}{*}{$p$} \\
\hline & \multicolumn{2}{|c|}{ Experimental } & \multicolumn{2}{|c|}{ Control } & \multicolumn{2}{|c|}{ Difference } & & & \\
\hline & $M$ & $S D$ & $M$ & $S D$ & $M$ & $S D$ & & & \\
\hline \multicolumn{10}{|c|}{ Experiment 2} \\
\hline Distracter & 4.22 & 2.55 & 1.58 & 1.63 & 2.64 & 2.30 & 9.75 & 71 & $<.001$ \\
\hline Prior List & 2.54 & 1.97 & 2.99 & 1.70 & -0.44 & 1.86 & -2.03 & 71 & .046 \\
\hline \multicolumn{10}{|c|}{ Experiment 3} \\
\hline Distracter & 3.58 & 3.33 & 1.37 & 1.26 & 2.21 & 3.01 & 6.22 & 71 & $<.001$ \\
\hline Prior List & 1.82 & 1.29 & 2.25 & 1.86 & -0.43 & 1.66 & -2.20 & 71 & .031 \\
\hline \multicolumn{10}{|c|}{ Experiment 4} \\
\hline Distracter & 1.53 & 1.23 & 0.56 & 0.77 & 0.97 & 1.21 & 6.82 & 71 & $<.001$ \\
\hline Prior List & 2.35 & 1.71 & 3.04 & 2.74 & -0.69 & 2.67 & -2.20 & 71 & .031 \\
\hline
\end{tabular}

Note: inferential statistic is a one-sample $t$ on the difference scores with zero as comparison value. 